\title{
¿Impacts of North Pacific Subtropical and Subarctic Oceanic Frontal Zones on the Wintertime Atmospheric Large-Scale Circulations
}

\author{
Jing Huang, Yang Zhang, Xiu-Qun Yang, Xuejuan Ren, and Haibo Hu \\ CMA-NJU Joint Laboratory for Climate Prediction Studies, Institute for Climate and Global Change Research, \\ School of Atmospheric Sciences, Nanjing University, Nanjing, China
}

(Manuscript received 25 April 2019, in final form 26 November 2019)

\begin{abstract}
An oceanic frontal zone is a confluent region of warm and cool ocean currents, characterized by a strong meridional gradient of sea surface temperature (SST). High-resolution SST observations show that the wintertime North Pacific exhibits a unique double-oceanic-front structure, with a subtropical frontal zone (STFZ) and a subarctic frontal zone (SAFZ), whose impacts on the weather and climate over the East Asia-North Pacific-North American region need further investigation. In this study, we conduct groups of multiyear and ensemble simulations using a WRF high-resolution regional climate model, through which the different impacts of the STFZ and SAFZ on the wintertime atmospheric circulations are identified and compared. Our multiyear simulations show that the STFZ, although with weaker intensity, exerts evident and consistent impacts on the storm track and westerly jet in the North Pacific by enhancing and elongating the eddy activity, zonal wind, and Aleutian low. The SAFZ exhibits coherent impacts on the low-level atmospheric baroclinicity and storm track; however, its impacts on the upper-level storm track and atmospheric circulations are divergent, exhibiting strong year-by-year difference. Our study suggests that the SAFZ's impacts on the atmospheric circulations strongly depend on the background mean state, which contributes to the divergent impacts of the SAFZ. Furthermore, our results highlight the role of diabatic heating for the above different impacts of the STFZ and SAFZ on the atmosphere. We argue that the much deeper diabatic heating induced by the STFZ, via affecting the baroclinicity through the whole troposphere, can exert consistent influence on eddy activities and atmospheric circulations.
\end{abstract}

\section{Introduction}

Oceanic frontal zones mark the dramatic confluence of warm and cool ocean currents, characterized by strong meridional sea surface temperature (SST) gradient. Many studies have shown that the oceanic frontal zones are the key regions of extratropical air-sea interactions in both Northern and Southern Hemispheres (e.g., Nakamura et al. 2004; Taguchi et al. 2009; Kwon et al. 2010; Frankignoul et al. 2011; Ogawa et al. 2016). A series of modeling studies using aquaplanet experiments with zonally uniform oceanic frontal zones, corresponding to the situation of Southern Hemispheric oceanic frontal zones, have been conducted (Nakamura et al. 2008; Sampe et al. 2010) and have found that the strongest midlatitude storm track as well as eddy-driven

๑ Denotes content that is immediately available upon publication as open access.

Corresponding author: Yang Zhang, yangzhang@nju.edu.cn jet are always organized along oceanic frontal zones in the extratropics. The impacts of the Gulf Stream front on the atmosphere in the North Atlantic also have been investigated by a series of works. The Gulf Stream front is found to significantly enhance the intensity of storm track in the lower troposphere and anchor the latitudinal position of the eddy-driven jet (Minobe et al. 2008; Kuwano-Yoshida et al. 2010; Small et al. 2014; O'Reilly et al. 2017).

However, the structures of oceanic frontal zones in the wintertime North Pacific are much more complicated. High-resolution observational data showed that oceanic frontal zones in North Pacific exhibit unique double large-scale fronts in the winter, with a subarctic frontal zone (SAFZ) and a subtropical oceanic frontal zone (STFZ) (Kazmin and Rienecker 1996; Nakamura et al. 1997; Dinniman and Rienecker 1999). The SAFZ is the more evident and stronger front in the wintertime North Pacific Ocean and is located in a joint region between the northern cooler ocean current associated with the Oyashio Extension and the southern warmer ocean 
current associated with the Kuroshio Extension. The SAFZ associated with Kuroshio-Oyashio Extension systems is suggested to be a key region of air-sea interactions in the North Pacific (Kelly et al. 2010; Kwon et al. 2010; Frankignoul et al. 2011). Both modeling and observational studies have been conducted to investigate its impacts on the midlatitude storm track. Taguchi et al. (2009), through a case study using the regional model, found that the SAFZ can effectively maintain near-surface baroclinicity in winter via "oceanic baroclinic adjustment" and retain the low-level storm-track activity. Such findings are further confirmed by other case studies using model simulations such as Yao et al. (2016). O'Reilly and Czaja (2015), through the analysis of observational data, also revealed that the strong SST front anchors more intense storm-track activity over the western Pacific in the lower troposphere. Therefore, most of the previous studies reached an agreement that the SAFZ can significantly maintain the near-surface baroclinicity and enhance the low-level storm-track activity in the wintertime North Pacific.

Relative to the impacts of the SAFZ on the low-level storm track, the SAFZ's impacts on the upper-level storm track and atmospheric circulations, however, show much less agreement. The case study of Taguchi et al. (2009) showed that the enhancement of storm track with the SAFZ is confined in the lower troposphere and much weaker in the upper troposphere. O'Reilly and Czaja (2015) found that the response of wintertime atmospheric circulation to the SST front exhibits dipole geopotential height anomalies in the eastern Pacific, while Kuwano-Yoshida and Minobe (2017) found that the SAFZ results in positive geopotential height anomalies over the Okhotsk Sea and Gulf of Alaska. Therefore, the impacts of SAFZ on the upper-tropospheric atmospheric circulation patterns are still controversial, needing further investigation and clarification.

Compared to the SAFZ, which has been extensively studied, many fewer studies have been conducted to investigate the impacts of STFZ on the atmosphere. The STFZ is probably associated with the Subtropical Countercurrent, which is a shallow ocean eastward current (Takeuchi 1984; Yamanaka et al. 2008). Despite its weaker intensity, the STFZ sits in the subtropical region with higher SST and moisture, implying great potential for transporting substantial heat and moisture to the atmosphere. Moreover, the STFZ is located in the central region of decadal-scale SST variability, the Pacific decadal oscillation (PDO), in the North Pacific (Nakamura et al. 1997; Fang and Yang 2016). Fang and Yang (2016) proposed a hypothesis for the wintertime ocean-atmosphere interaction on the decadal time scale. In their hypothesis, the STFZ is an indispensable ingredient in the coupled system. By anchoring the atmospheric transient eddies that interact with the largescale circulations, the STFZ may act as a link between the SST anomalies associated with the PDO and the atmospheric westerly jet. Such a hypothesis, especially on the role of STFZ in the climate system, calls for more evidence and comprehensive studies to identify the impacts of STFZ.

The purpose of this study is to identify the different impacts of STFZ and SAFZ on the wintertime atmospheric large-scale circulations. Furthermore, the relative importance of SAFZ and of STFZ to the wintertime atmospheric circulations are compared and discussed. Instead of case studies, we conduct groups of multiyear and ensemble simulations using the relatively highresolution regional model. Our results show that the STFZ, although with weaker intensity, exhibits evident and consistent impacts on the storm track and atmospheric circulations in the wintertime North Pacific. The SAFZ's impacts on the upper-level storm track and atmospheric circulations, however, exhibit great yearby-year differences, which we show are strongly affected by the different background states in each year. We further argue that the different impacts of STFZ and SAFZ on the atmosphere can be attributed to the different roles of diabatic heating on the uppertropospheric baroclinicity.

The rest of the paper is organized as follows. Section 2 describes the detailed setup of model experiments. Section 3 evaluates the model performance by comparing with observations. Sections 4 and 5 investigate the impacts of STFZ and SAFZ, respectively, on the wintertime atmospheric large-scale circulations. The reasons for the different impacts of STFZ and SAFZ on the atmosphere are explored in section 6. Conclusions and discussion are presented in section 7 .

\section{Model experiment}

We use the Weather Research and Forecasting (WRF) Model, version 3.4.1 (Skamarock et al. 2008), developed by National Center for Atmospheric Research (NCAR) to investigate the different impacts of SAFZ and STFZ on the atmosphere. The model can well simulate the amplitude and the location of the wintertime storm track and atmospheric large-scale circulations in the North Pacific (Yao et al. 2016; Ma et al. 2017). The simulation domain in this study covers the whole North Pacific $\left(12^{\circ}-63^{\circ} \mathrm{N}, 116^{\circ} \mathrm{E}-103^{\circ} \mathrm{W}\right)$. The model is set with the horizontal resolution of $30 \mathrm{~km}$ including 384 grids in zonal direction and 190 grids in meridional direction, which is sufficient to well simulate the impacts of 
the fine structures of SAFZ and STFZ on the atmosphere. The model has 35 sigma levels in the vertical direction from surface to $10 \mathrm{hPa}$. A series of physics schemes in the model, which are suitable for the North Pacific (Tanimoto et al. 2011), are listed below:

- Longwave radiation: Rapid Radiative Transfer Model (Mlawer et al. 1997)

- Shortwave radiation: Dudhia scheme (Dudhia 1989)

- Land surface: Noah land surface scheme (Chen and Dudhia 2001)

- Planetary boundary layer: asymmetric convective model, version 2 (Pleim and Chang 1992)

- Cumulus parameterization: Betts-Miller-Janjic scheme (Betts and Miller 1986; Janjić 1994)

- Microphysics: WRF double-moment 6-class scheme (Lim and Hong 2010)

The initial conditions, lateral boundary, and lower boundary conditions in the numerical experiments are all derived from Global Forecast System (GFS) Final Operational Global Analysis (FNL; available online at https://rda.ucar.edu/datasets/ds083.2/) with 6-hourly temporal resolution. We simulate 15 winters from 2000 to $2015 .{ }^{1}$ Here, the winter refers to the period from November to April in the next year (NDJFMA). In all simulations, the model is initialized at 1 November of each year, with the first two months as spinup period. The statistics of each winter are analyzed based on the model outputs from January to March. The lateral boundary conditions are updated every $6 \mathrm{~h}$.

The SST is set as the lower boundary conditions in all simulations. The SST is fixed during the simulation time and four experiments are carried out for comparison for each year. As shown in Fig. 1, the observational winter mean meridional SST gradient of each year is decomposed into two components: background SST gradient and frontal-scale SST gradient. The background SST is performed by applying a nine-point running-mean filter in both meridional and zonal direction 90 times on the winter mean SST. The frontal-scale SST is the difference between the winter mean SST and the background SST. Then four experiments are carried out for each year based on different lower boundary SST conditions, as summarized in Table 1 . The control run (referred to as CTL run) is the experiment in which the lower boundary condition is set as the observational winter mean SST of the year. The background run (referred to as the BG run) is the experiment with the background SST as the

\footnotetext{
${ }^{1}$ The winter of $2007 / 08$ is excluded in our study, because the
TFFZ and SAFZ in this winter are merged and thus it is hard to

${ }^{1}$ The winter of $2007 / 08$ is excluded in our study, because the
STFZ and SAFZ in this winter are merged and thus it is hard to separate their impacts on the atmospheric large-scale circulations.
}
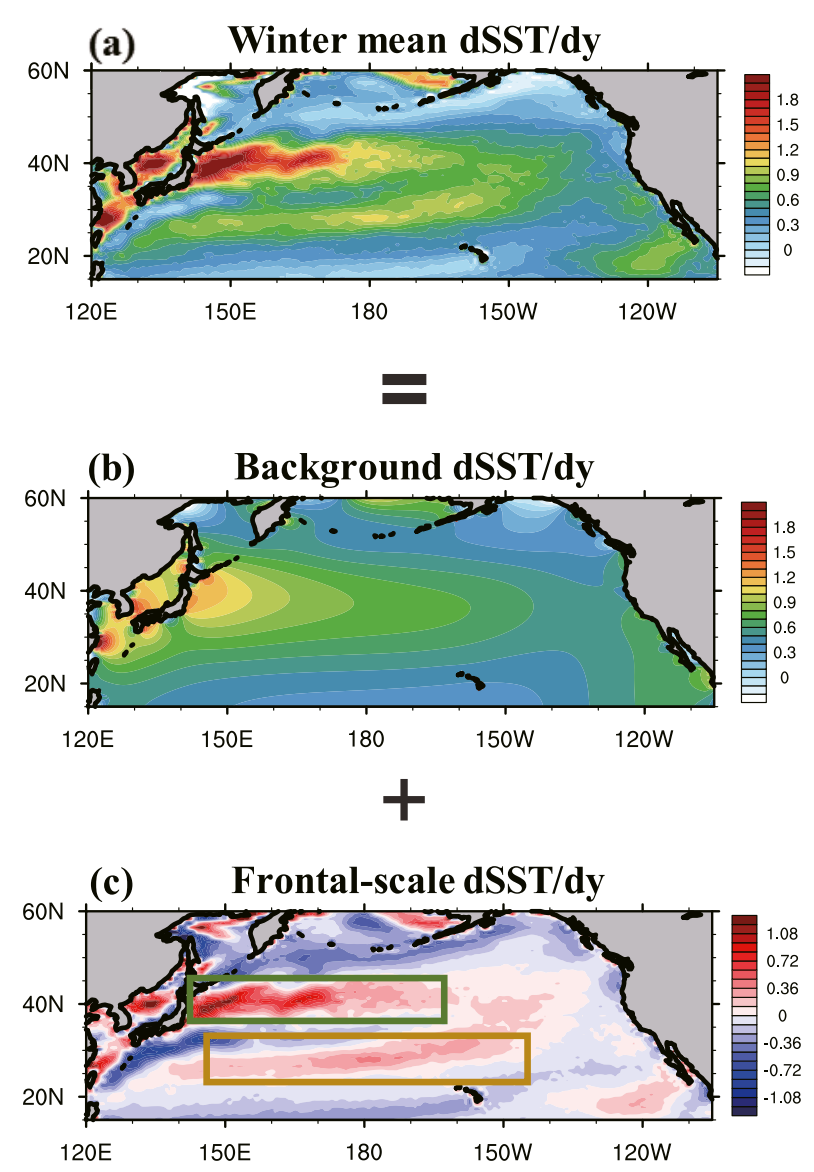

FIG. 1. Diagram illustrating the decomposition of winter mean $d \mathrm{SST} / d y$ in each year's simulation. (a) Winter mean $d \mathrm{SST} / d y$ of the year is decomposed into (b) background $d \mathrm{SST} / d y$ and (c) frontalscale $d \mathrm{SST} / d y\left[\mathrm{~K}(100 \mathrm{~km})^{-1}\right.$; note that $\left.(\mathrm{b})+(\mathrm{c})=(\mathrm{a})\right]$. The green and yellow boxes in (c) represent the regions of SAFZ and STFZ, respectively. Note that $d S S T / d y$ in each panel uses the multiyear mean observed SST as an example. The $d \mathrm{SST} / d y$ values in each simulation year all exhibits similar spatial patterns to that in the multiyear mean.

lower boundary condition, in which the sharp SST gradient associated with SAFZ and STFZ are both eliminated while the large-scale SST variabilities such as ENSO or PDO signal are still kept. The SAFZ and STFZ runs are set up to investigate the impacts of SAFZ and STFZ on the atmospheric circulation, respectively. For the SAFZ run, only the SAFZ is included in the model, in which the lower boundary condition is set as the background SST plus frontal-scale SST associated with the SAFZ as displayed in Figs. 2a and 2c. For the STFZ run, the background SST plus frontal-scale SST associated with the STFZ is used as the lower boundary condition (Figs. 2b,d). The differences of the atmospheric responses between the SAFZ runs (STFZ runs) and background runs are regarded as the impacts of the SAFZ (STFZ) on the wintertime atmospheric circulations. 
TABLE 1. Lower boundary conditions for the experiments in each year.

\begin{tabular}{lc}
\hline \hline Run & \multicolumn{1}{c}{ Lower boundary condition } \\
\hline CTL & $\begin{array}{c}\text { Observational winter mean SST of the simulation year } \\
\text { Applying a nine-point running-mean filter in the meridi- } \\
\text { onal and zonal direction } 90 \text { times on the SST in CTL run } \\
\text { Background SST in BG run and frontal-scale SST } \\
\text { associated with SAFZ of the year } \\
\text { SAFZ } \\
\text { STFZ } \\
\text { Background SST in BG run and frontal-scale SST } \\
\text { associated with STFZ of the year }\end{array}$ \\
\hline
\end{tabular}

As suggested by previous studies (Deser et al. 2014; Seo et al. 2017), the atmospheric responses to external forcing could be mixed with the internal atmospheric variability. Thus, in addition to the multiyear simulations, we conducted ensemble experiments as well to eliminate the influence of the internal atmospheric variability on the atmospheric response to the oceanic frontal zone forcing. Due to the extremely expensive computational time, we conducted 16 -member ensemble simulations only for two typical winters, the winters of 2008/09 and 2015/16. Each ensemble member owns identical lateral and lower boundary conditions, only with the initial condition slightly perturbed. The initial conditions of the 16-member ensemble are chosen at 0000, 0600, 1200, and 1800 UTC 1-4 November, as in Zeng et al. (2016). By investigating the multiyear simulations and ensemble simulations, we aim to obtain robust results on the impacts of the two oceanic frontal zones on the atmospheric circulations.

\section{The results of CTL runs}

We first examine the performance of our model by comparing the results of CTL runs with high-resolution observations. The Climate Forecast System Reanalysis (CFSR) developed by National Centers for Environmental Prediction (NCEP) with $0.5^{\circ}$ horizontal resolution (Saha et al. 2010) is applied for comparison with the model outputs of the atmospheric variables. Surface turbulent heat flux data from Objectively Analyzed Air-Sea Fluxes (OAFlux) with $1^{\circ}$ resolution ( $\mathrm{Yu}$ and Weller 2007) are also used to validate the reliability of the model simulations.

Figures $3 \mathrm{a}$ and $3 \mathrm{~b}$ compare the winter mean surface turbulent heat flux in CTL runs with the observations. Here, the surface turbulent heat flux is the sum of the surface sensible and latent heat flux. In the observation, the climatological winter mean surface turbulent heat flux reaches the maximum value over the south of the SAFZ and a second peak over the south of the STFZ. The surface turbulent heat flux in CTL runs shows a similar spatial pattern to the observations, especially for the location of the double peaks (Fig. 3b), although overestimated by $30 \%$ in intensity in the model. The similar overestimation of surface turbulent heat flux is also reported in many previous studies in their atmospheric runs (e.g., Yao et al. 2016), in which the fixed SST and thus limited air-sea coupling may attribute to the amplified surface turbulent heat flux.

Figures $3 c$ and $3 d$ compare the near-surface baroclinicity, which is denoted by the meridional gradient of $1000-\mathrm{hPa}$ air temperature. In the observation, the distribution of the near-surface baroclinic zone exhibits bimodal structure, which exactly corresponds to the double oceanic frontal zones in the North Pacific. The strongest one is located along the region of the SAFZ and the second one is located in the region of the STFZ. The model well simulates
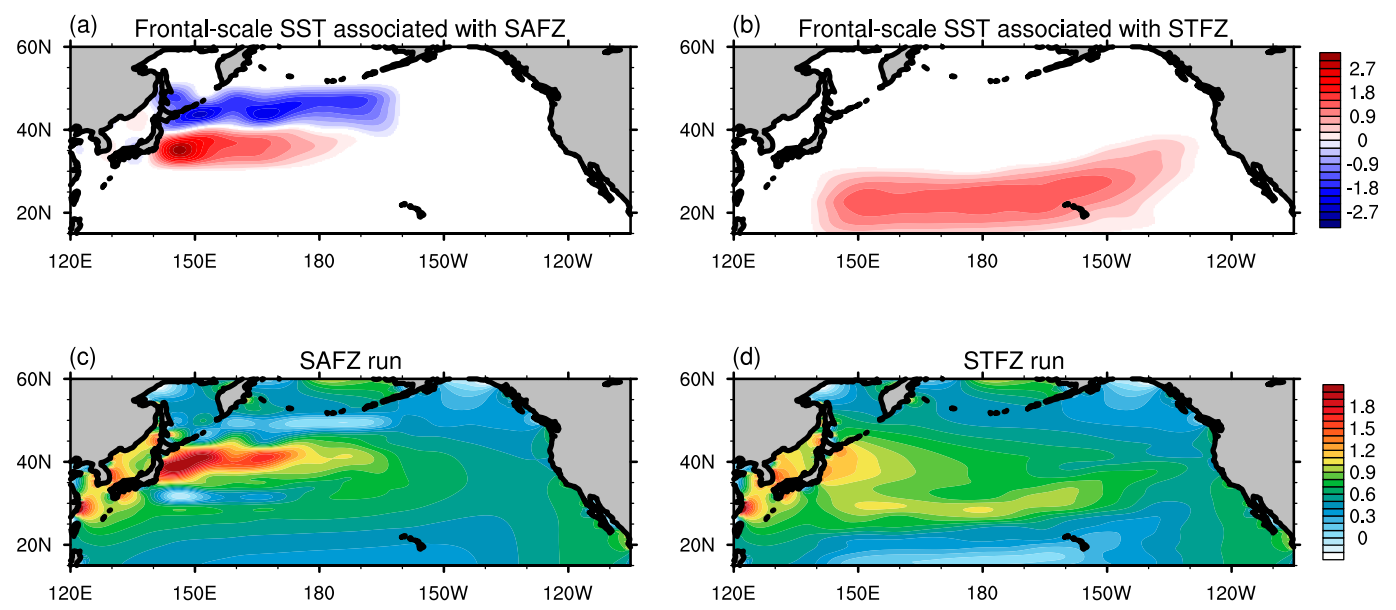

FIG. 2. (top) The winter mean distributions of the local SST forcing (K) associated with the (a) SAFZ and (b) STFZ runs. (bottom) The meridional SST gradient $\left[\mathrm{K}(100 \mathrm{~km})^{-1}\right]$ in the (c) SAFZ and STFZ runs. 


\section{Obs}
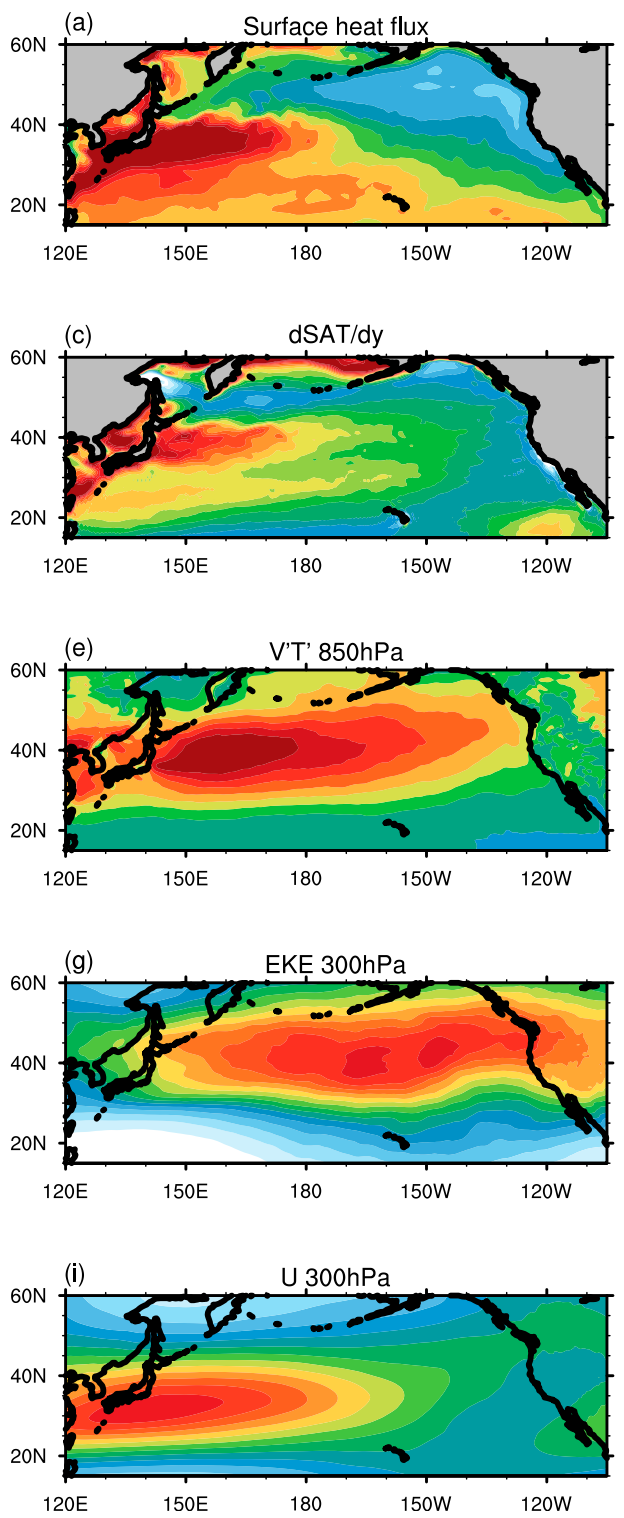

CTL
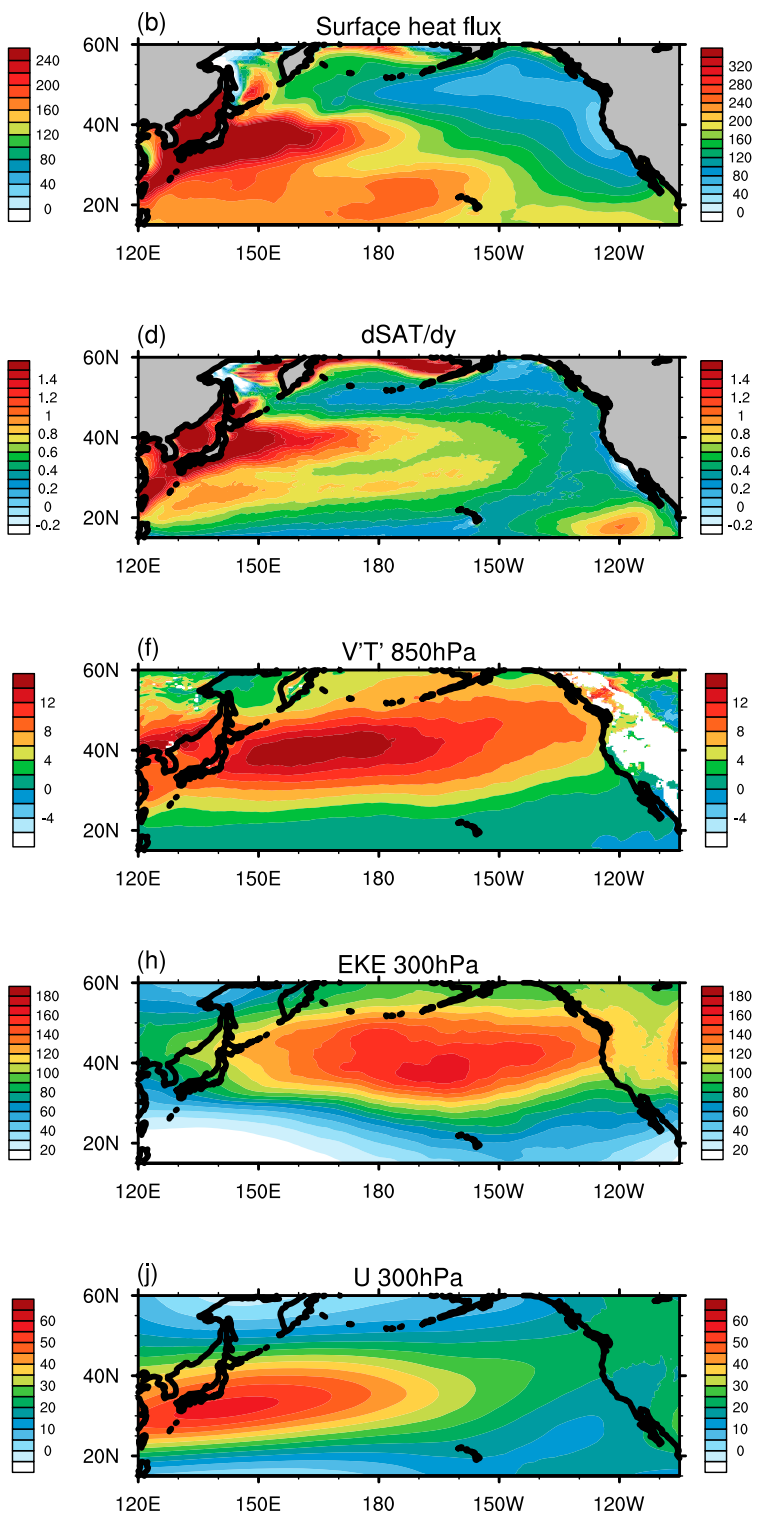

FIG. 3. The multiyear mean wintertime (a) surface turbulent heat flux $\left(\mathrm{W} \mathrm{m}^{-2}\right)$, (c) meridional surface air temperature gradient $\left[\mathrm{K}(100 \mathrm{~km})^{-1}\right.$ ], (e) synoptic-scale transient eddy poleward heat flux at $850 \mathrm{hPa}$ $\left(\mathrm{m} \mathrm{s}^{-1} \mathrm{~K}\right),(\mathrm{g})$ synoptic-scale transient eddy kinetic energy at $300 \mathrm{hPa}\left(\mathrm{m}^{2} \mathrm{~s}^{-2}\right)$, and (i) zonal wind at $300 \mathrm{hPa}$ $\left(\mathrm{m} \mathrm{s}^{-1}\right)$ from the observational data. (b), (d),(f),(h),(j) As in (a), (c), (e), (g), and (i), respectively, but from the CTL runs.

the bimodal pattern of the near-surface baroclinic zone corresponding to the double oceanic fronts, with the amplitudes comparable to that of observations.

Figures $3 \mathrm{e}$ and $3 \mathrm{f}$ compare low-level storm track between observations and model simulations. The lowlevel storm-track activity is measured by the $850-\mathrm{hPa}$ poleward eddy heat flux $v^{\prime} T^{\prime}$ (Taguchi et al. 2009), in which the prime refers to the synoptic-scale transient eddy with a time scale of $2-10$ days. The low-level storm track in the observation reaches a maximum along the SAFZ in the western North Pacific. The low-level storm track in the CTL runs exhibits a similar pattern with comparable magnitude to the observation in the whole North Pacific. The core of the storm track in the observation is broader than that in the CTL runs in the meridional direction. This may be attributed to the north-south shift of the SAFZ in winter in reality, which is missing in our simulations with fixed SST. 
Figures $3 \mathrm{~g}$ and $3 \mathrm{~h}$ further compare the upper-level storm track between observations and model simulations, which is measured by the $300-\mathrm{hPa}$ transient eddy kinetic energy (EKE), defined as $\left(u^{\prime 2}+v^{\prime 2}\right) / 2$ (Taguchi et al. 2009). The observed maximum of the upperlevel storm track is located over central to eastern North Pacific, downstream of the near-surface baroclinic zone. The simulated storm track in the CTL runs reproduces a similar pattern to observations, except the somewhat underestimated EKE over the North American continent, at the east edge of the domain. The model well captures the structure of upper-level zonal wind especially for the westerly jet stream for its amplitude and position (Figs. 3i,j). Both the observation and model simulation exhibit the prevailing westerly jet stream, which is concentrated along $30^{\circ} \mathrm{N}$, extending from the western to eastern North Pacific. All the above comparisons show that our model can well simulate the wintertime largescale atmospheric circulations and storm track in the North Pacific, and thus can be used to investigate the impacts of the STFZ and SAFZ on the wintertime atmospheric circulations.

\section{Impacts of the STFZ on wintertime storm track and large-scale atmospheric circulations}

\section{a. Impacts of the STFZ on baroclinicity and storm track}

We begin with investigating the impacts of STFZ on the near-surface baroclinicity, which is a key factor for the growth and development of the storm track (Hoskins and Valdes 1990; Nakamura et al. 2004). Figures $4 a-c$ show the responses of surface heat flux, surface air temperature, and surface air temperature gradient (dominant factor of baroclinicity), respectively, to the underlying STFZ. The surface turbulent heat flux in Fig. 4a is evidently enhanced along the subtropical region, exhibiting similar spatial pattern to the SST forcing in STFZ runs (Fig. 2b). Such response is consistent with the observations in Figs. 3a and $3 \mathrm{~b}$, suggesting that the observed subtropical peak of surface turbulent heat flux is closely bound up with the STFZ. The response of the surface air temperature in Fig. $4 \mathrm{~b}$ mostly follows the changes of SST and surface heat flux. Strong positive temperature anomalies are found in the southward region of the STFZ, indicating that the warm SST significantly heats the air temperature through surface turbulent heat flux. Along with the changes of surface air temperature, the meridional gradient of surface air temperature (Fig. 4c) is significantly enhanced along the STFZ, corresponding
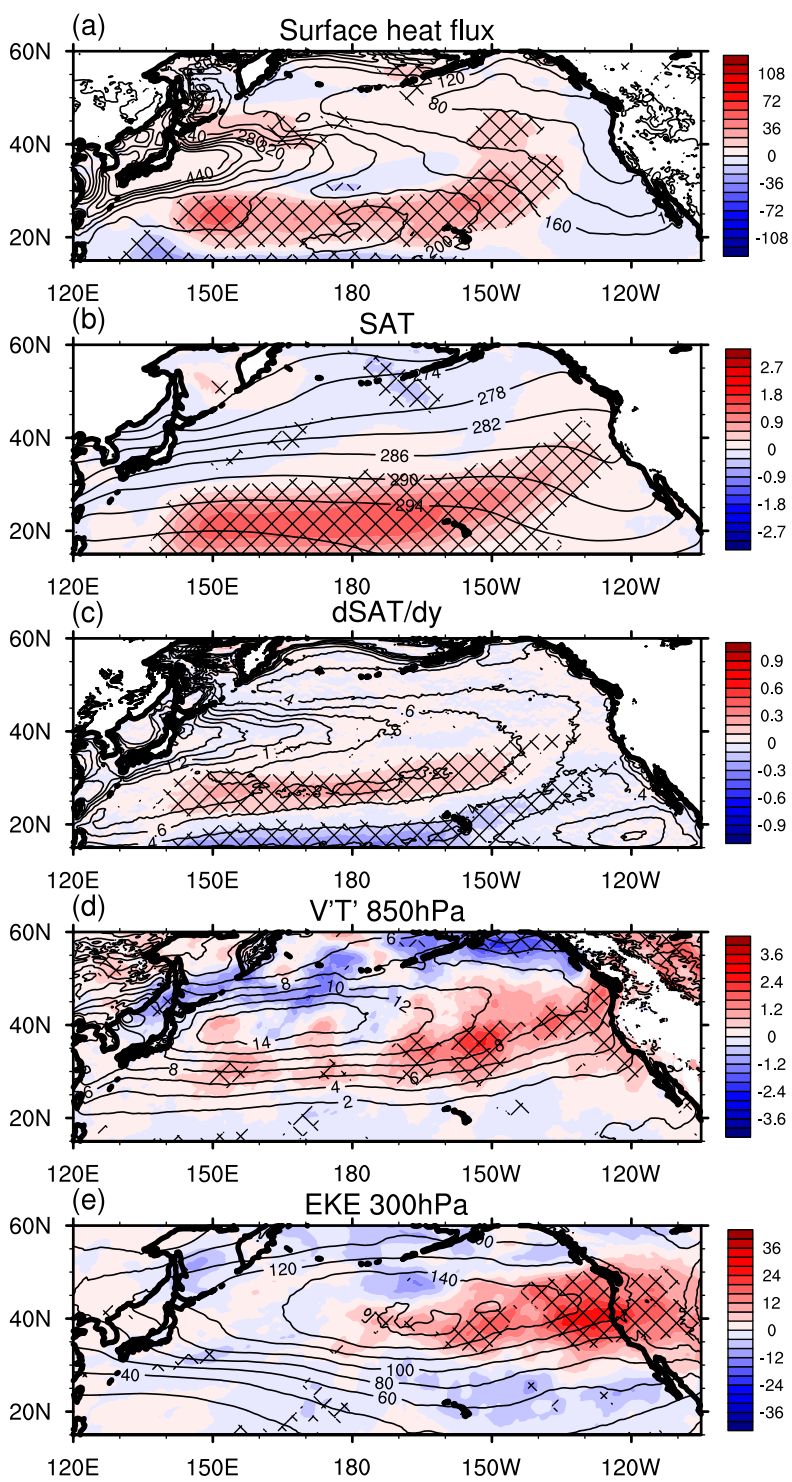

FIG. 4. The multiyear mean responses of (a) surface turbulent heat flux (shaded; $\mathrm{W} \mathrm{m}^{-2}$ ), (b) surface air temperature (shaded; $\mathrm{K}$ ), (c) meridional surface air temperature gradient [shaded; K $\left.(100 \mathrm{~km})^{-1}\right]$, (d) synoptic-scale transient eddy poleward heat flux at $850 \mathrm{hPa}$ (shaded; $\mathrm{m} \mathrm{s}^{-1} \mathrm{~K}$ ), and (e) synoptic-scale transient eddy kinetic energy at $300 \mathrm{hPa}$ (shaded; $\mathrm{m}^{2} \mathrm{~s}^{-2}$ ) to STFZ. The contours represent the multiyear mean in CTL runs. Values above the $95 \%$ confidence level of Student's $t$ test are denoted by hatched lines.

to the second peak of the near-surface baroclinicity in observation (Fig. 3c).

The response of the low-level storm track, which is measured by the 850 -hPa poleward heat flux $v^{\prime} T^{\prime}$ of synoptic eddies, is illustrated in Fig. 4d. In response to the STFZ, the low-level storm track is significantly strengthened from the central North Pacific to the western coast of North American continent, which is the downstream region of the enhanced 
low-level baroclinicity in Fig. 4c. In the upper troposphere, the response of EKE shows that the upperlevel storm track is strongly enhanced from the eastern North Pacific to the North American continent along $40^{\circ} \mathrm{N}$ (Fig. $4 \mathrm{e}$ ), consistent with the response of low-level eddy activities. The responses of lower- and upper-level storm track all show that the STFZ can reinforce the downstream eddy activity and thus elongate the storm track eastward, which can exert significant influences on the regional weather and climate over the North American continent (Ma and Chang 2017).

\section{b. Impacts of the STFZ on large-scale atmospheric circulations}

The impacts of the STFZ on the large-scale atmospheric circulations are shown in Fig. 5. The response of the sea level pressure (SLP) to STFZ shows evident low pressure anomalies over the Gulf of Alaska. The response of the geopotential height at $300 \mathrm{hPa}$ displays similar negative anomalies over the Gulf of Alaska, thus exhibiting an equivalent barotropic response (Fig. 5b). Such an equivalent barotropic response over the Gulf of Alaska suggests an eastward shift of the center of the Aleutian low in the whole troposphere. In contrast, over the subtropical region, the responses of SLP and upper-level geopotential height are out of phase with negative anomalies for SLP and positive anomalies for geopotential height at $300 \mathrm{hPa}$. Such a baroclinic structure implies that the response in the subtropical region is likely thermally forced by the local warm SST forcing (Fig. 2b).

The spatial structures of westerly jet are changed correspondingly. Figures $5 \mathrm{c}$ and $5 \mathrm{~d}$ display the responses of lower- and upper-level zonal wind velocities to STFZ, respectively. In the midlatitudes, the westerly jets are strengthened downstream of the jet core in both lower and upper levels, suggesting that the jet stream is elongated eastward. It is noted that the responses of westerly jet to STFZ in the midlatitude exhibit different vertical structures between the western and eastern North Pacific. Over the western North Pacific, the westerly jet is characterized by a baroclinic structure, in which the enhancement mostly occurs in the upper troposphere and turns to be much weaker in the lower level. Over the eastern North Pacific, the westerly jet is enhanced through the whole troposphere with an equivalent barotropic structure. In the subtropical and high latitudes, the zonal winds are reduced in both lower and upper levels.

To further understand the barotropic structure of the jet response to STFZ, the changes of the transient eddy feedback onto the mean flow are further investigated.

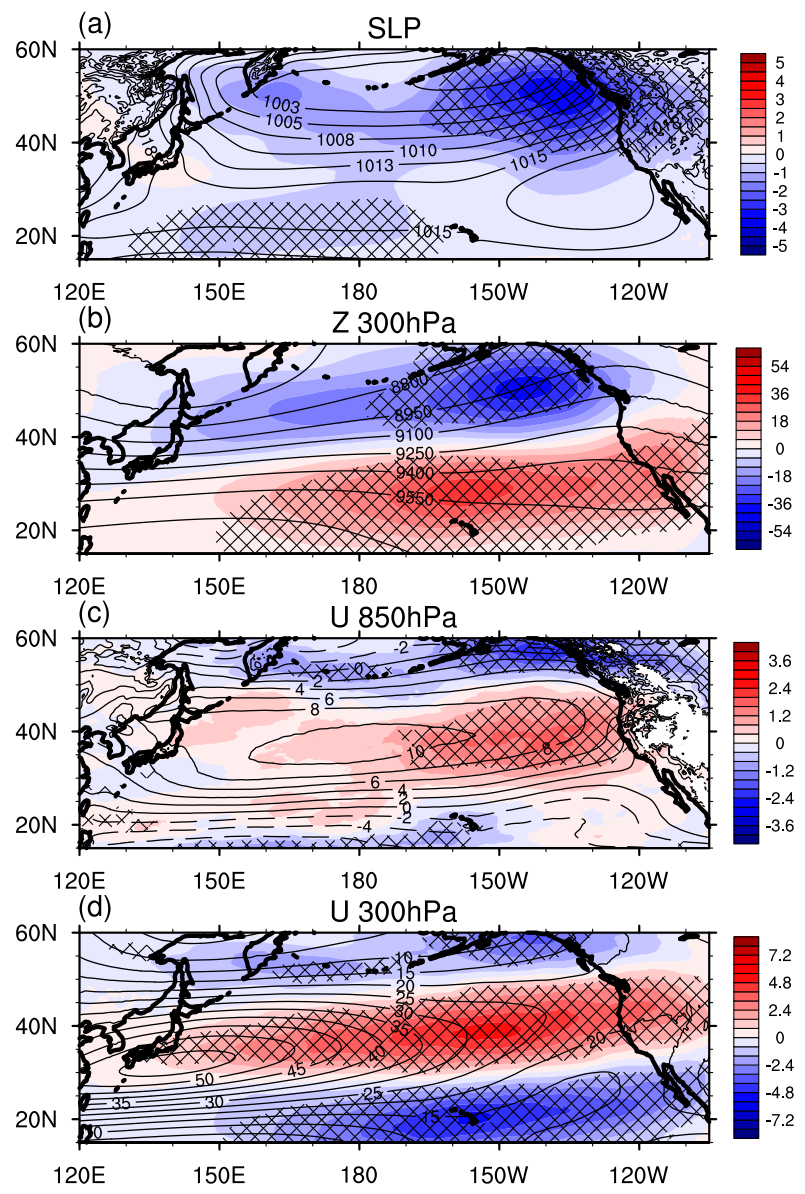

FIG. 5. The multiyear mean responses of (a) sea level pressure (shaded; hPa), (b) geopotential height at $300 \mathrm{hPa}$ (shaded; $\mathrm{m}$ ), (c) zonal wind at $850 \mathrm{hPa}$ (shaded; $\mathrm{m} \mathrm{s}^{-1}$ ), and (d) zonal wind at $300 \mathrm{hPa}$ (shaded; $\mathrm{m} \mathrm{s}^{-1}$ ) to the STFZ. The contours represent the multiyear mean in CTL runs. Values above the $95 \%$ confidence level of Student's $t$ test are denoted by hatched lines.

The $\mathbf{E}$ vector is applied to quantify the eddy feedback (Hoskins et al. 1983):

$$
\mathbf{E}=\left(\overline{v^{\prime 2}-u^{\prime 2}},-\overline{u^{\prime} v^{\prime}}, \frac{f \overline{v^{\prime} \theta^{\prime}}}{\partial \bar{\theta} / \partial p}\right),
$$

in which the prime denotes 2-10-day high-frequency eddy component and the overbar represents the corresponding winter mean. The $\mathbf{E}$ vector divergence is proportional to the zonal wind tendency, with the divergence (convergence) of the $\mathbf{E}$ vector acting to accelerate (decelerate) the westerly wind velocity. Figure 6 shows the $\mathbf{E}$ vector divergence at $300 \mathrm{hPa}$ in the North Pacific. In both STFZ runs and BG runs, the divergence of the $\mathbf{E}$ vector extends from the East Asian continent to the eastern North Pacific, reaching maximum around $40^{\circ} \mathrm{N}$ over the central North Pacific. The difference between the two runs occurs mostly 

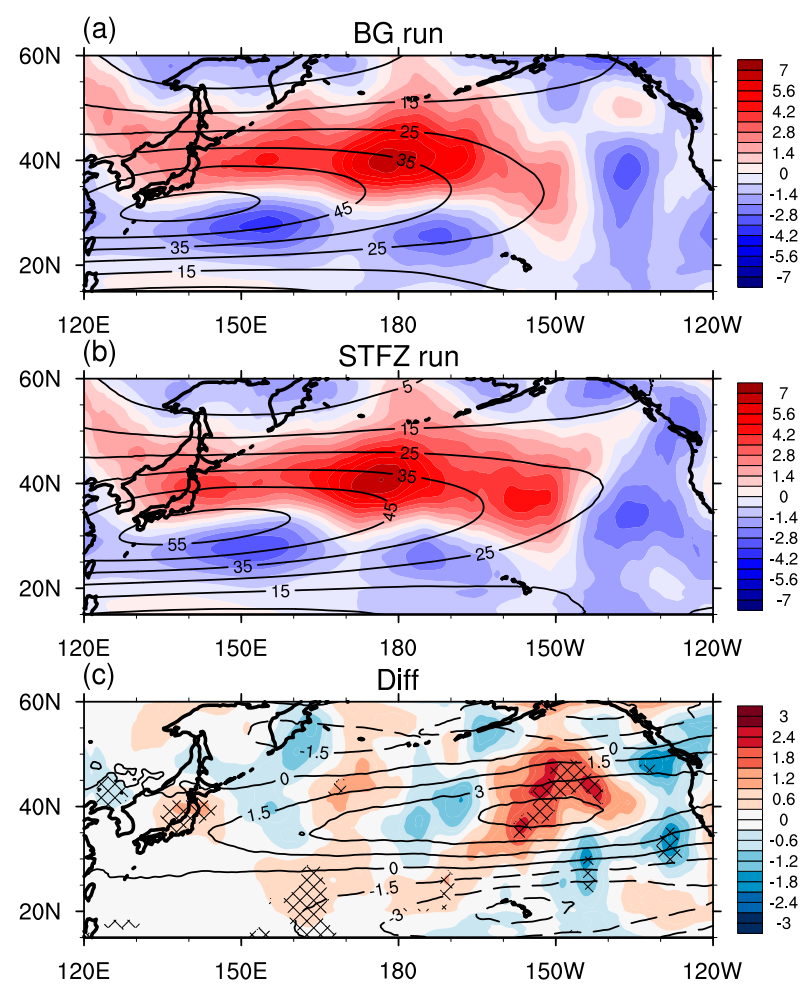

FIG. 6. The multiyear mean of $\nabla \cdot \mathbf{E}$ (shaded; $10^{-5} \mathrm{~m} \mathrm{~s}^{-2}$ ) and zonal wind (contours; $\mathrm{m} \mathrm{s}^{-1}$ ) at $300 \mathrm{hPa}$ in the (a) BG and (b) STFZ runs, and (c) the difference between the STFZ and BG runs. Values above the $95 \%$ confidence level of Student's $t$ test are denoted by hatched lines.

in the eastern North Pacific. Such downstream enhanced divergence of the $\mathbf{E}$ vector contributes to the equivalent barotropic response of the westerly jet over the region.

In addition to the eddy response, we also check the response of local Hadley circulation to STFZ, given that the changes of Hadley circulation are suggested to be important in the atmospheric responses to the zonal uniform SST gradient in aquaplanet simulations as in Brayshaw et al. (2008). We found that the changes of local Hadley circulation exhibit distinct differences in western and eastern North Pacific, with weakened Hadley circulation in the west and enhanced circulation in the east. Such changes of Hadley circulation are found to play a secondary role in the atmospheric responses to STFZ (results thus not shown).

In summary, the STFZ exerts evident impacts on the baroclinicity, eddy activity, and large-scale circulations in the atmosphere. The STFZ, via surface heat flux, can result in strong low-level baroclinicity in the atmosphere above it, along with which the eddy activity in its downstream region is significantly enhanced in both the lower and upper troposphere. The large-scale circulations in midlatitudes such as the Aleutian low and westerly jet all exhibit eastward extension and intensification in the whole troposphere, consistent with the downstream enhancement of the storm track and its feedback on the mean flow. The changes of the circulation in the subtropics, however, exhibit vertically baroclinic structure, implying the direct role of thermal heating. The warm SST forcing (Fig. 2b) added in the STFZ run triggers deep convective heating in the region and induces divergence (convergence) flow in the upper (lower) troposphere, which also acts to enhance the upper-level westerly zonal wind. A similar direct thermal response was reported in previous modeling and observational studies as well (Hoskins and Karoly 1981; Kushnir 1994; Fang and Yang 2016). The role of diabatic heating will be further discussed in section 6 .

\section{Impacts of SAFZ on wintertime storm track and large-scale atmospheric circulations}

\section{a. Impacts of SAFZ on baroclinicity and storm track}

The impacts of SAFZ on the low-level baroclinicity are also first investigated. Figures $7 \mathrm{a}-\mathrm{c}$ show the responses of surface turbulent heat flux, surface air temperature, and surface air temperature gradient to the SAFZ, respectively. The response of surface turbulent heat flux in Fig. 7a exhibits significant enhancement in the warmer flank of the SAFZ and decreases in the cooler flank, exhibiting a similar spatial pattern to the SST forcing in the SAFZ runs (Fig. 2a). The changes of surface turbulent heat flux further affect surface air temperature by warming the surface air temperature in the south and cooling it in the north (Fig. 7b). Accompanied with the changes of surface air temperature, the meridional gradient of surface air temperature is evidently strengthened along the SAFZ (Fig. 7c).

The response of low-level storm track to the SAFZ is displayed in Fig. 7d. The low-level heat flux of synoptic eddies is strongly enhanced, especially in the region where the eddy heat flux is climatologically strongest. Such enhancement of the low-level storm track is also in agreement with the previous case studies (Taguchi et al. 2009; Yao et al. 2016). The eddy activity in the flanks of the core regions is significantly reduced, which is consistent with the reduced meridional gradient of the surface air temperature. However, the response of the upper-tropospheric eddy activity is unexpectedly weak. The upper-level EKE even decreases in the eastern North Pacific, exhibiting different responses in the upper level compared to that in the lower level. 

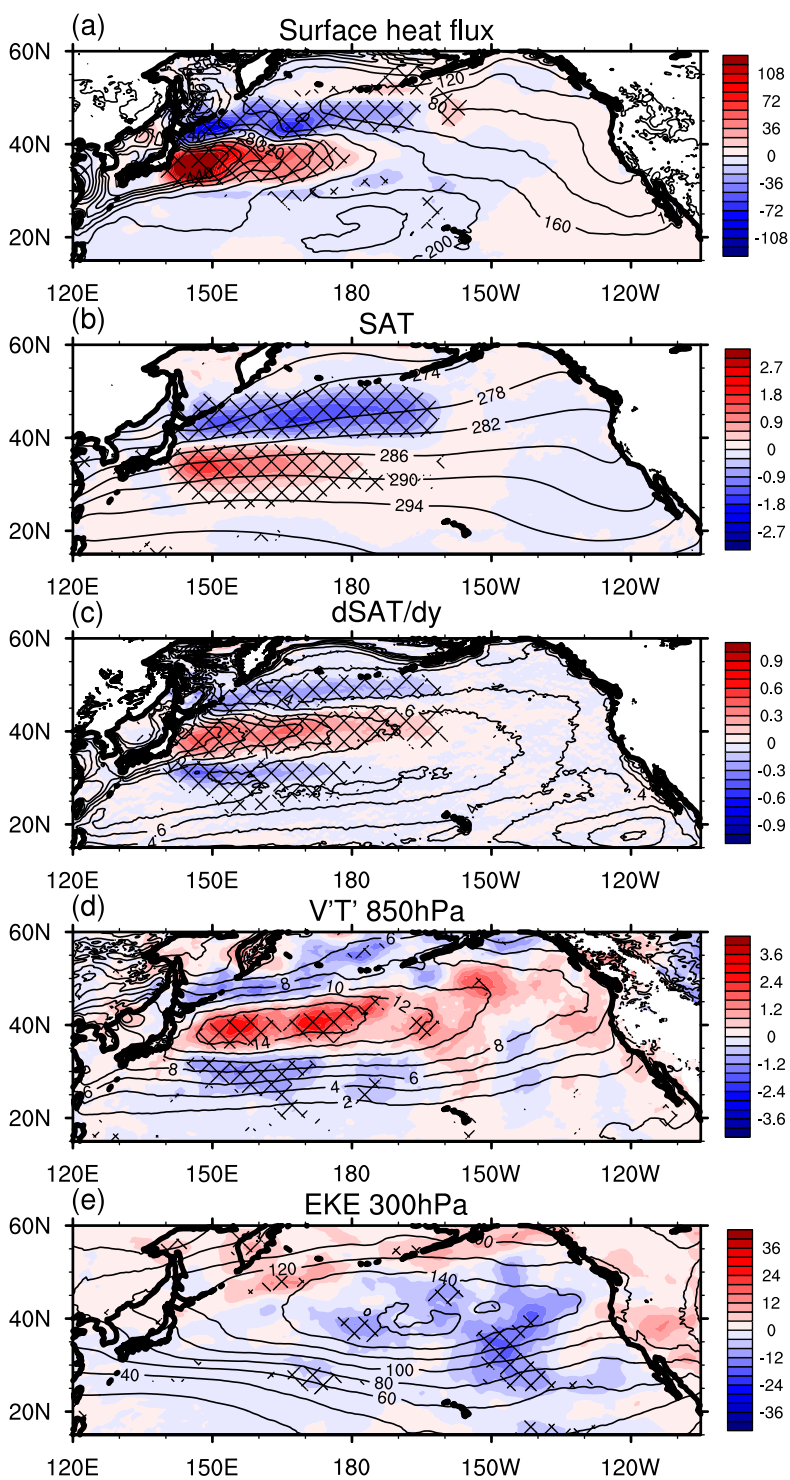

FIG. 7. As in Fig. 4, but for the multiyear mean responses to the SAFZ.

\section{b. Impacts of $S A F Z$ on large-scale atmospheric circulations}

The impacts of SAFZ on the large-scale atmospheric circulations are displayed in Fig. 8. The SLP responses to the SAFZ are weak and very few areas can pass the significance test. There are only significant low pressure anomalies within the warmer side of the SAFZ, which is also revealed by Tanimoto et al. (2011). The response of geopotential height at $300 \mathrm{hPa}$ is weak and insignificant as well, which is dominated by the positive anomalies in the North Pacific (Fig. 8b). The responses of zonal wind are weaker and cannot pass significant test in both lower and upper levels. In summary, although the forcing of the SAFZ is much stronger in intensity than that of the
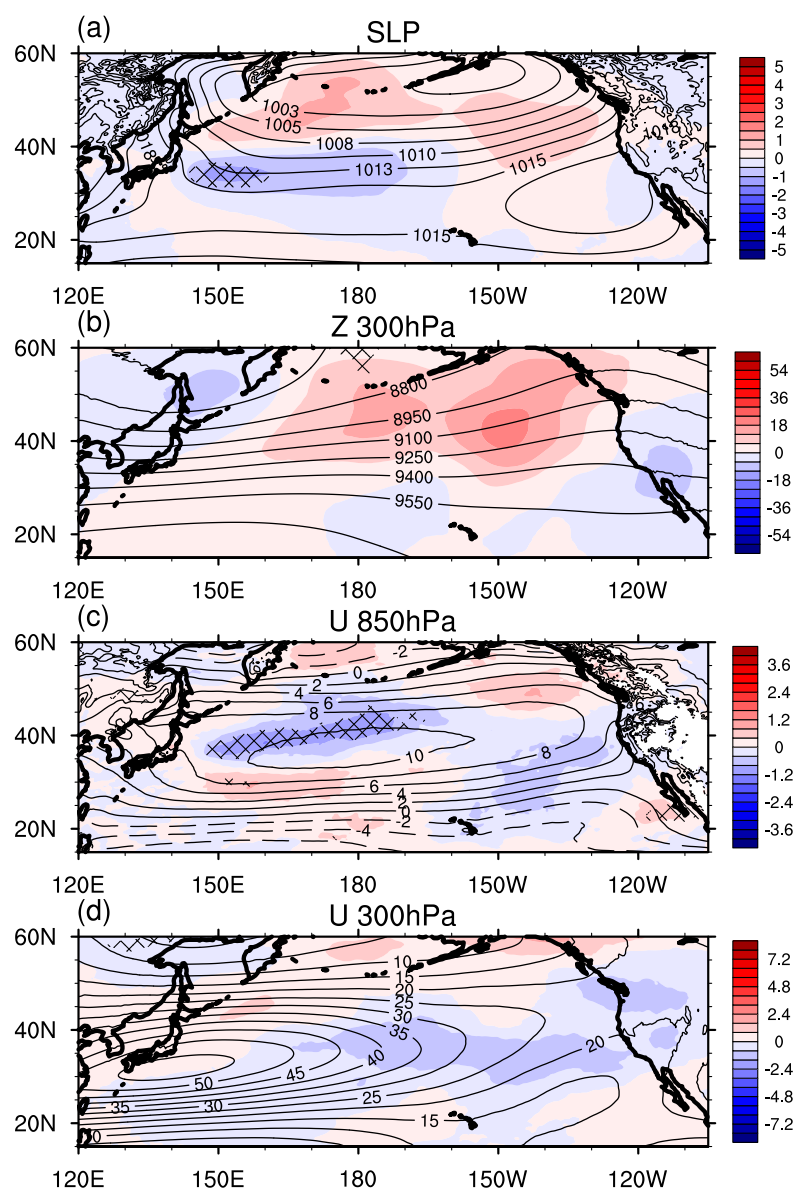

FIG. 8. As in Fig. 5, but for the multiyear mean responses to the SAFZ.

STFZ, the responses of the atmospheric large-scale circulations are much weaker and insignificant. The reasons for such weak responses are further investigated.

\section{c. Year-by-year difference in the responses to $S A F Z$}

We examine the year-by-year atmospheric responses to SAFZ to understand why the multiyear mean responses of upper-level storm track and atmospheric circulations are weak and insignificant. We find that their responses to SAFZ exhibit great year-by-year differences in both the spatial pattern and intensity (results not shown), although the responses of the lowerlevel baroclinicity and storm track are consistent in each year. Such strong year-by-year differences are therefore responsible for their weak and insignificant responses of the multiyear mean of the simulations. The SAFZ forcing in each year exhibits very similar patterns to those in Figs. 2a and 2c, although with the year-byyear difference in intensity. To investigate why the similar patterns of SST forcing result in such divergent responses in the upper-level storm track and the 


\section{5/2016}

\section{8/2009}
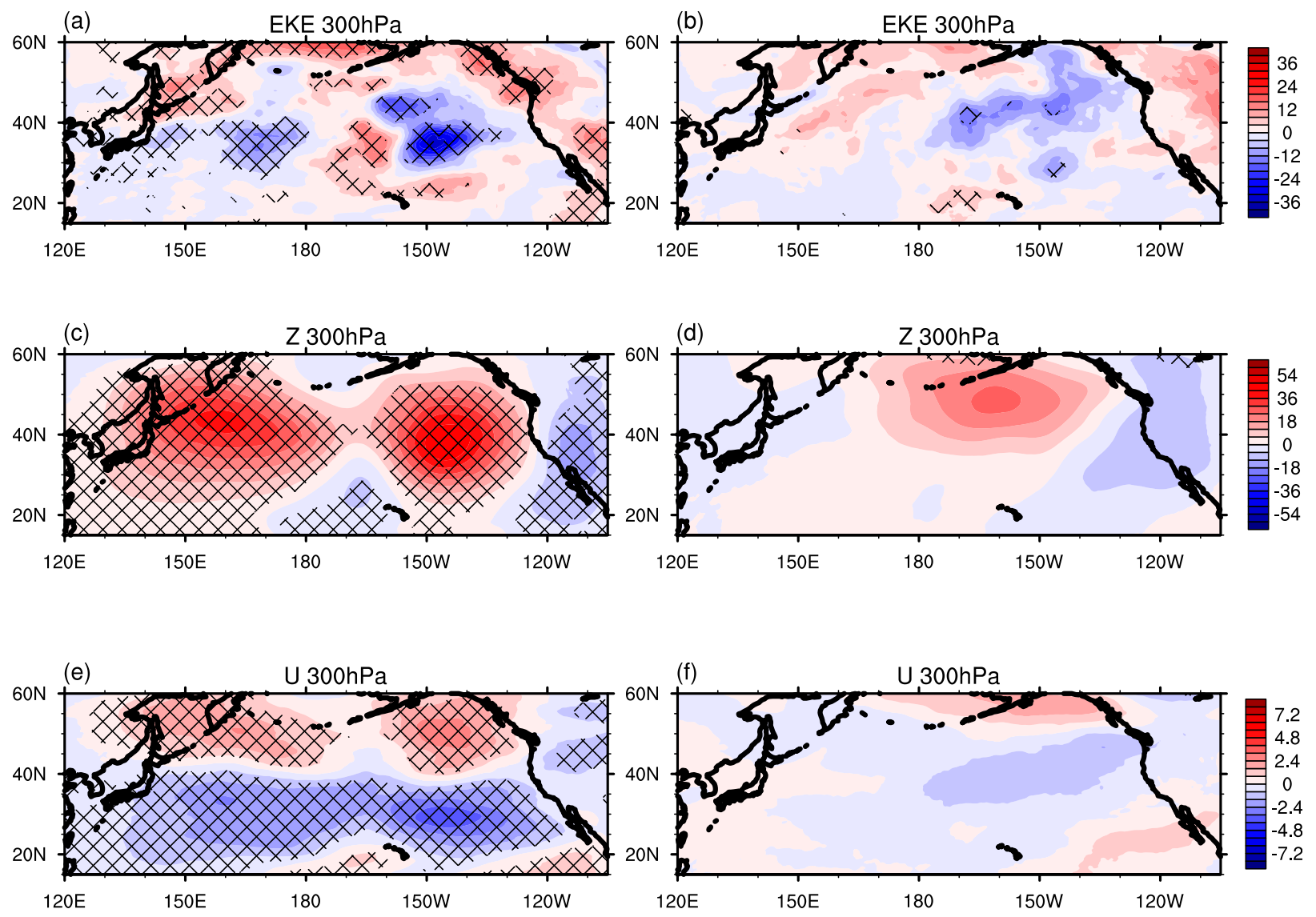

FIG. 9. The ensemble-mean responses of (a) synoptic-scale transient eddy kinetic energy at $300 \mathrm{hPa}\left(\mathrm{m}^{2} \mathrm{~s}^{-2}\right)$, (c) geopotential height at $300 \mathrm{hPa}$ (shaded; $\mathrm{m}$ ), and (e) zonal wind at $300 \mathrm{hPa}$ (shaded; $\mathrm{m} \mathrm{s}^{-1}$ ) to the SAFZ in the winter of 2015/16. (b),(d),(f) As in (a), (c), and (e), but for the winter of 2008/09. Values above the $95 \%$ confidence level of Student's $t$ test are denoted by hatched lines.

atmospheric circulations, we further check the roles of background states and internal variabilities in the different year-by-year responses to the SAFZ, which are the two likeliest candidates for the divergent responses given the previous studies (Peng et al. 1997; Taguchi et al. 2012; Deser et al. 2014; Thomson and Vallis 2018). Thus, we choose two typical winters with evidently different background mean states, the winters of 2014/15 and $2008 / 09$, to further understand the atmospheric responses. Both the background SST and the background atmospheric states are different in the two winters, making them suitable for us to investigate the influence of background mean states. Furthermore, 16-member ensemble simulations are carried out in the two winters to exclude the influence of the internal atmospheric variability as in Deser et al. (2014).

Figure 9 displays the responses of upper-level storm track and atmospheric circulations to the SAFZ in the ensemble simulations of the two winters. The ensemblemean responses still exhibit evident year-by-year differences. The winter of 2015/16 shows strong and evident responses. The EKE in the upper troposphere is greatly enhanced in the broad north of $40^{\circ} \mathrm{N}$ and reduced in the south of $40^{\circ} \mathrm{N}$, indicating that the upper-level storm track has a widespread shift poleward (Fig. 9a). The responses of geopotential height in the winter of 2015/16 in Fig. 9c are dominated by the positive anomalies with the maximum in the regions from the East China Sea to the central and eastern North Pacific. Correspondingly, the westerly zonal wind is intensified to the north of $40^{\circ} \mathrm{N}$ and weakened to the south of $40^{\circ} \mathrm{N}$, indicating a northward shift of the westerly jet (Fig. 9e). Similar responses of atmospheric circulations to the SAFZ were also reported by Kuwano-Yoshida and Minobe (2017) using a high-resolution GCM, although their study was not based on ensemble simulations thus may be mixed up with internal atmospheric variability. In contrast to the winter of 2015/16, the responses in winter of 2008/09 to the SAFZ exhibit different features in both upper-level storm track and 
(a) 2008/2009 SAFZ+2015/2016 Background

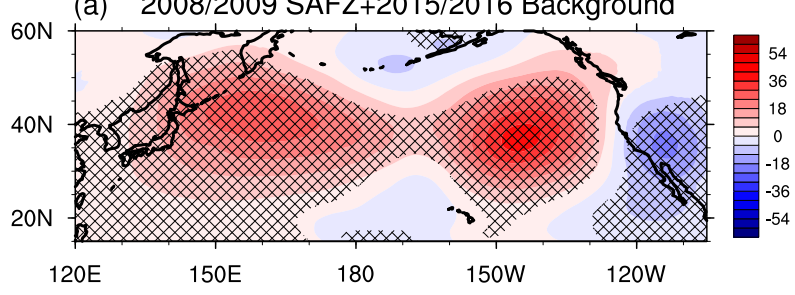

(b) 2015/2016 SAFZ+2008/2009 Background

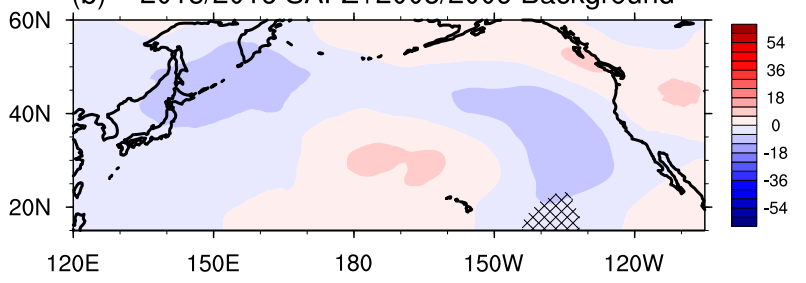

FIG. 10. The ensemble-mean responses of geopotential height at $300 \mathrm{hPa}$ (shaded; $\mathrm{m}$ ) to SAFZ based on (a) frontal-scale SST associated with the SAFZ in the winter of 2008/09 and the background state in the winter of 2015/16 and (b) frontal-scale SST associated with the SAFZ in the winter of 2015/16 and the background state in the winter of 2008/09 (shaded; m). Values above the $95 \%$ confidence level of Student's $t$ test are denoted by hatched lines.

large-scale atmospheric circulations, in which the responses are very weak and insignificant (Figs. 9b,d,f). The above results of the ensemble simulations in the two winters suggest that the strong year-by-year differences in the responses of upper-level storm track and largescale atmospheric circulations to SAFZ are most likely attributable to the different background states.

Additional ensemble simulations are carried out to further confirm the dominant role of background states in the different year-by-year responses to SAFZ. The ensemble simulations keep the frontal-scale SST associated with SAFZ unchanged in the two winters but use the background mean states in the other winter, which is determined by the background SST and lateral boundary conditions. That is, in the winter of 2015/16 (2008/09), we use the frontal-scale SST forcing of 2015/ $16(2008 / 09)$ and the background states in the winter of 2008/09 (2015/16). Comparing Fig. 10 with Figs. 9c and $9 \mathrm{~d}$, the simulation results show that the response patterns to SAFZ are more dominantly determined by the background states, compared with the frontal-scale SST forcing. The former is the primary factor that determines the year-by-year difference in the responses to SAFZ.

We further investigate why the different background states can result in different upper-tropospheric responses to SAFZ. Figure 11 shows the spatial distributions of upper-level zonal wind in the BG runs of the two winters, which reflects their different background
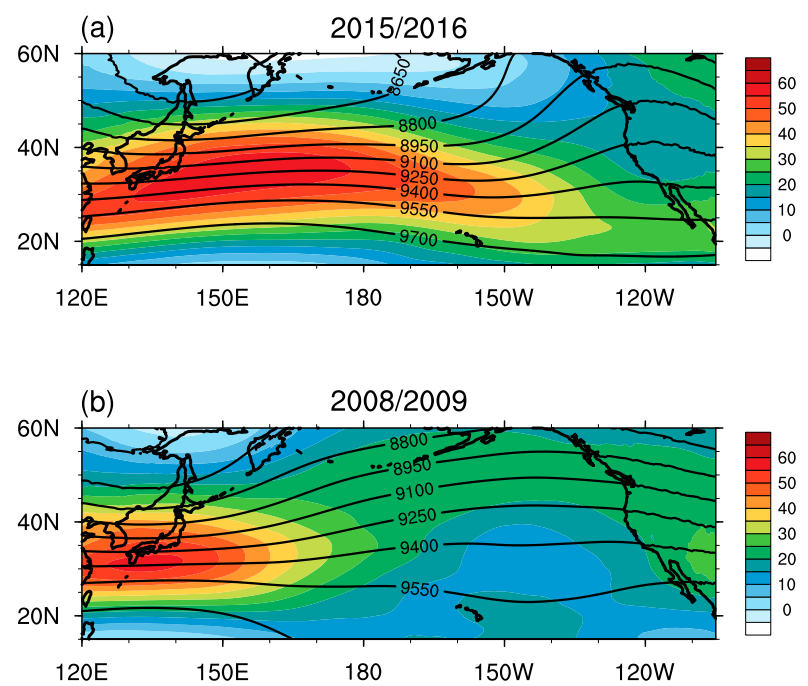

FIG. 11. The ensemble mean of zonal wind at $300 \mathrm{hPa}$ (shaded; $\mathrm{m} \mathrm{s}^{-1}$ ) and geopotential height at $300 \mathrm{hPa}$ (contours; $\mathrm{m}$ ) in winters of (a) 2015/16 and (b) 2008/09 in the BG runs.

mean states. In the winter of $2015 / 16$, the background westerly jet in the upper troposphere is strong and broad, extending from the East Asian continent to the eastern North Pacific. In contrast, the background westerly jet in the winter of 2008/09 is much weaker and narrower, confined in the western North Pacific (Fig. 11b). Associated with the different background atmospheric states, the background SST in the winter of 2015/16 exhibits cold anomalies from the western Bering Sea to the midlatitude central North Pacific, and warm anomalies along the west coast of North American continent, compared to that in the winter of 2008/09 (results not shown).

With such different background states, we find that the transient eddy responses to the SAFZ also exhibit evident divergence. Figure 12 shows the verticallongitudinal distributions of the anomalous $\mathbf{E}$ vector of synoptic and low-frequency eddies in the two winters in response to the SAFZ. Here, the low-frequency eddy refers to the transient eddy with a 10-30-day time scale. In the winter of 2015/16, both the synoptic and lowfrequency eddies are increased near the surface of the upstream region and their responses can reach up to the whole troposphere probably through the vertical flux of the $\mathbf{E}$ vector. It is worthwhile to note that the enhanced eddies of both synoptic and low-frequency eddies propagate toward the strong background westerly jet core and thus strong eddy-mean flow interaction occurs, which can be responsible for the strong and evident responses of the upper-level storm track and atmospheric circulations in the winter of 2015/16. Such behavior of eddies is analogous to the situation in 
2015/2016

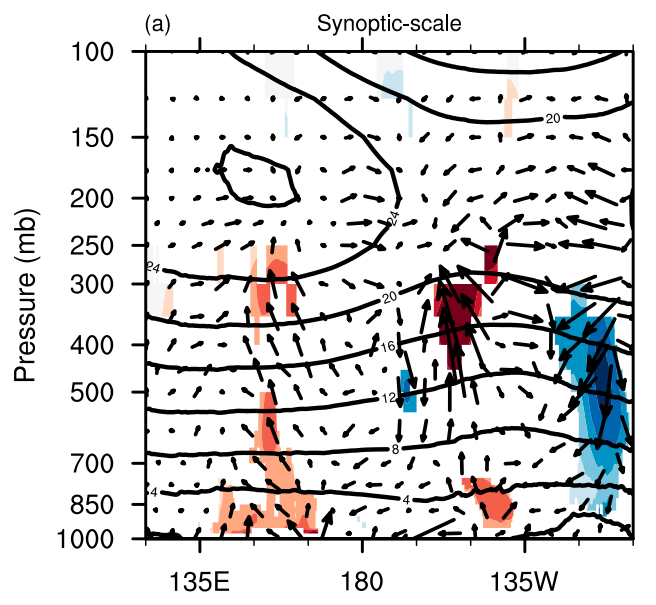

2008/2009

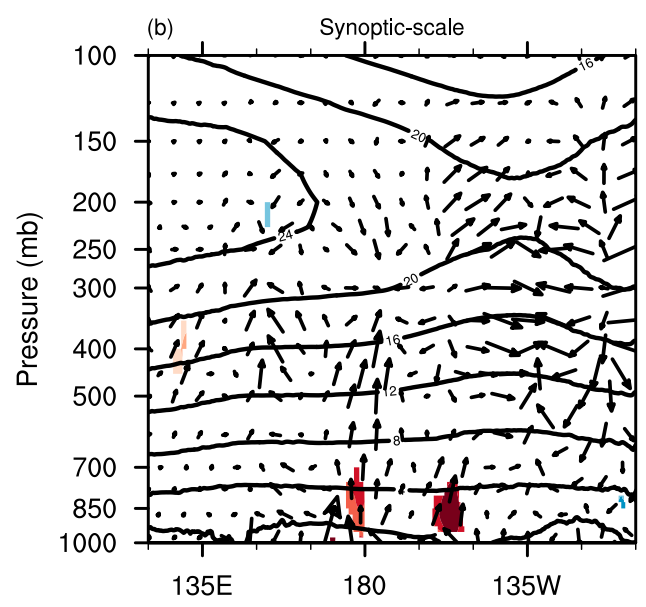

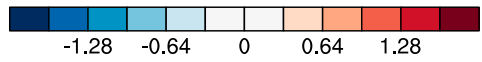
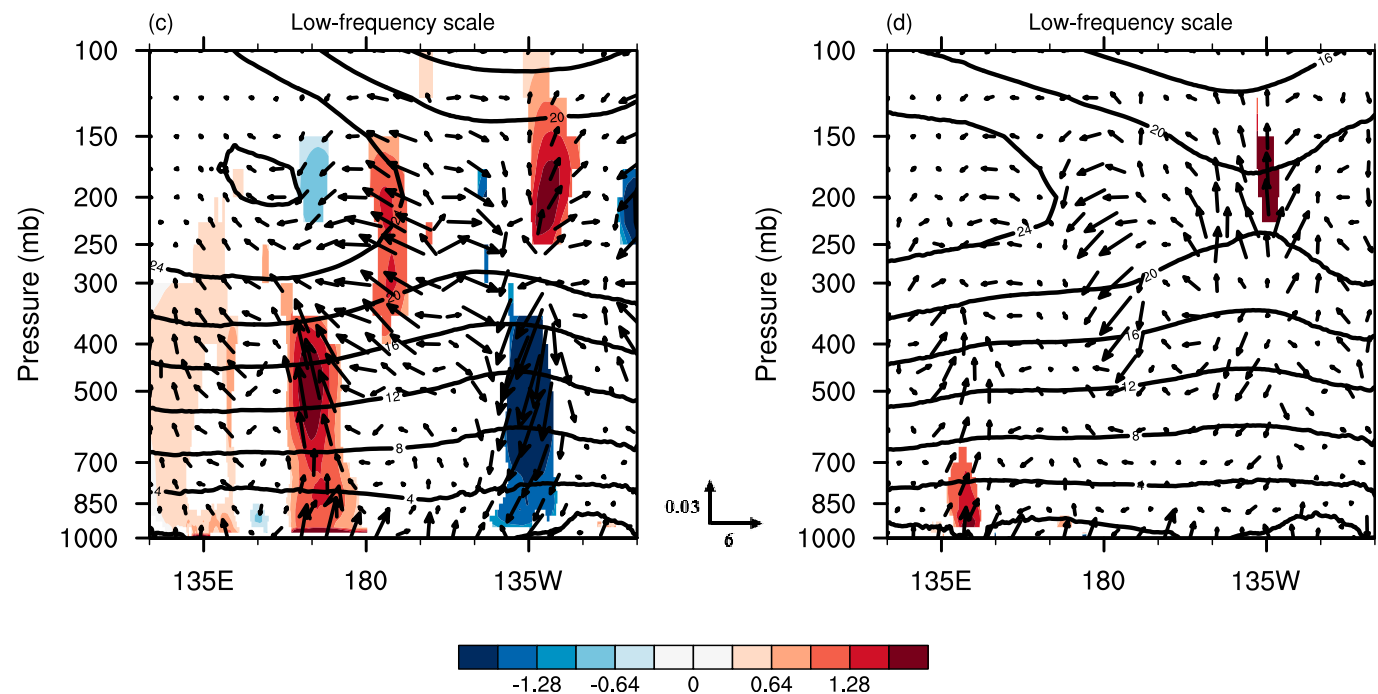

FIG. 12. The ensemble-mean responses of the $\mathbf{E}$ vector (arrows; $\mathrm{m}^{2} \mathrm{~s}^{-2}$ ) and its vertical component (shaded; $\mathrm{m}^{2} \mathrm{~s}^{-2}$ ) to SAFZ for (a) synoptic and (c) low-frequency eddies in the winter of $2015 / 16$, averaged between $30^{\circ}$ and $60^{\circ} \mathrm{N}$. (b),(d) As in (a) and (c), but for the winter of 2008/09. The thick contours in (a) and (c) and in (b) and (d) denote the zonal wind in BG runs in the winter of 2015/16 and 2008/09, respectively. In all panels, only the vertical components above the $95 \%$ confidence level of Student's $t$ test are color shaded.

Lee and Kim (2003) and Nie et al. (2016), in which eddies always behave in a more wave-like way following the guide of background westerlies in the strong and deep westerly belt. This helps us understand the more organized eddy response in the winter of 2015/16, with significant upward propagation toward the upper-level jet core region. In the winter of 2008/09, however, the responses of synoptic and low-frequency eddies are only confined in the lower level, and cannot significantly reach up further with the weak background westerlies
(Figs. 12b,d). Such vertically confined response cannot cause effective eddy-mean flow interactions, which can be responsible for the weak and insignificant response of atmospheric circulations. A similar simulation was also found in Nie et al. (2016), in which the eddy response to surface thermal forcing in idealized model is confined in the lower-level and uncoupled with the upper troposphere under weak background westerlies. Furthermore, the background westerly jet core in the winter of 2008/09 resides farther south away from SAFZ 
than that in year 2015/16 (Figs. 11a,b). As suggested by Nakamura and Sampe (2002), such greater latitudinal distance between the westerly jet core and surface baroclinic zone, more favorable for eddies trapping in the two regions, can also result in less effective vertical coupling of transient eddies and weaker eddy feedback on atmospheric circulations (Taguchi et al. 2012).

In summary, the SAFZ exhibits consistent impacts on the low-level atmospheric baroclinicity and storm track in the multiyear simulations. However, its impacts on the upper-level storm track and atmospheric circulations are weak and insignificant in the multiyear mean. This is directly attributed to the great year-by-year differences in the responses of upper-level storm track and atmospheric circulations to SAFZ. We argued that the year-by-year differences strongly depend on the background mean states. With the strong and downstream elongated westerly jet, the responses of transient eddies can penetrate through the whole troposphere, interact with the atmospheric circulations, and result in significant changes of the large-scale circulations. With the weak and confined westerly jet, eddy responses are mostly confined near the surface, which cannot interact with the large-scale circulations.

\section{Different responses between STFZ and SAFZ: Role of diabatic heating on upper-tropospheric baroclinicity}

In previous sections, we have showed that the STFZ, although with weaker intensity, exerts consistent and strong impacts on the wintertime atmosphere under different background states (also see the appendix for more details). However, the SAFZ's impacts on the upper-level storm track and atmospheric circulation exhibit great year-by-year differences, which depends on the background mean states. In this section, we further explore why the atmospheric responses to the STFZ and SAFZ have such evident differences.

We compare the atmospheric responses to the STFZ and SAFZ in more detail and find that their resultant diabatic heating in the atmosphere exhibits distinct features. Figure 13a shows the vertical distributions of diabatic heating in response to the STFZ. Deep and strong diabatic heating is observed in the warmer side of STFZ forcing, where warmer SST is added and heats up the above atmosphere. The diabatic heating reaches up into the upper troposphere, up to a maximum of $300 \mathrm{hPa}$. This is possibly due to the fact that the warmer SST with STFZ is located in the subtropical regions and can still trigger the convection releasing deep diabatic heating. With such deep diabatic heating, the enhancement of atmospheric baroclinicity in response to
STFZ extends from surface to $300 \mathrm{hPa}$ as well (Fig. 13c). In contrast, the diabatic heating in response to SAFZ exhibits much shallower patterns, although its intensity is stronger in the lower troposphere. Most of the anomalous diabatic heating occurs below the $500 \mathrm{hPa}$ and it rapidly decays in the upper levels (Fig. 13b). The modeling results are in agreement with the relatively shallow diabatic heating along the Kuroshio Extension in the winter revealed by Minobe et al. (2010). With the shallow diabatic heating, the enhancement of baroclinicity is limited in the lower level, below $500 \mathrm{hPa}$ (Fig. 13d).

Therefore, with different vertical extension of diabatic heating, the vertical profiles of the enhanced baroclinicity in response to the STFZ and SAFZ also exhibit evident differences. The impacts of the STFZ on the baroclinicity can penetrate the whole troposphere via diabatic heating. In contrast, the enhanced baroclinicity in response to the SAFZ is confined in the lower level. The theoretical study of Yuval and Kaspi (2016) has shown that, compared to the low-level baroclinicity, the baroclinicity in the upper troposphere is more efficient for eddy generation, which can result in stronger eddy response. However, the eddy responses to the changes of low-level baroclinicity exhibit distinct features, in which the transient eddies are mostly generated and confined in the lower level. In such a situation, as suggested in the theoretical study of Nie et al. (2016), the eddy responses in the upper and lower levels are uncoupled. The changes of eddy dissipation dominate the eddy response in the upper level. The upward extension of the eddies generated in the lower level and the upper-level eddy dissipation all depend on the background mean states, which could be responsible for the year-by-year differences in the responses of the upper-level eddy and the large-scale circulations to the SAFZ.

\section{Summary and discussion}

This study identifies the different impacts of the STFZ and SAFZ on the wintertime atmospheric largescale circulations by conducting groups of multiyear and ensemble simulations using the high-resolution WRF Model. Many previous studies have suggested the important role of the SAFZ in the extratropical air-sea interactions (Taguchi et al. 2009; Yao et al. 2016; O'Reilly and Czaja 2015; Kuwano-Yoshida and Minobe 2017). Our study highlights the importance of the STFZ for the atmospheric circulations. We show that, although with weaker intensity, the impacts of the STFZ on the atmosphere are at least as strong as the SAFZ. The STFZ shows an evident and consistent influence on the upper and lower tropospheric circulations in each year, 


\section{STFZ}

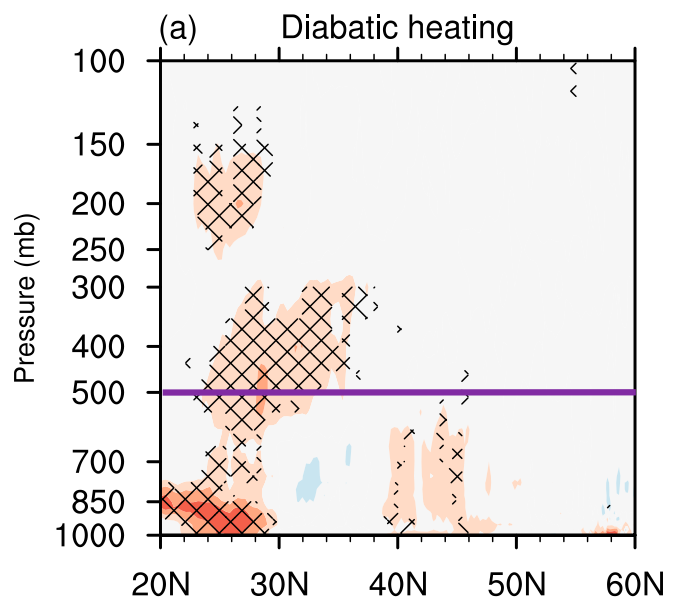

SAFZ

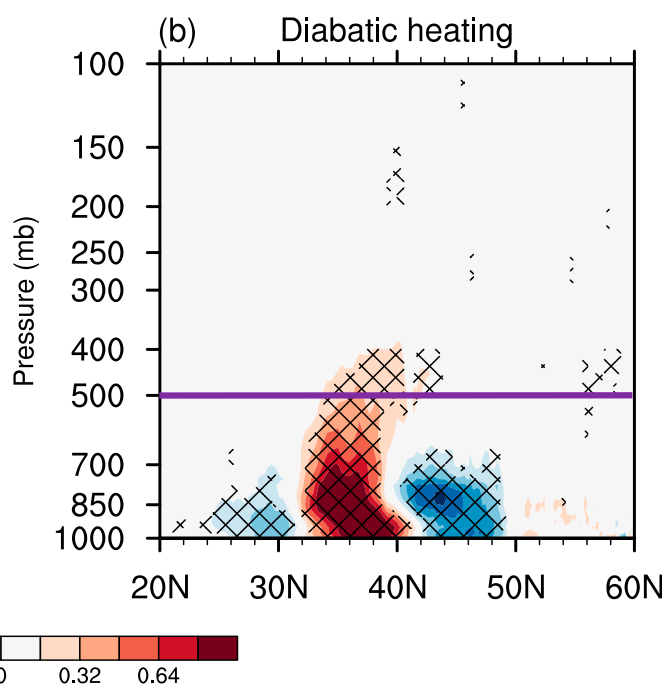

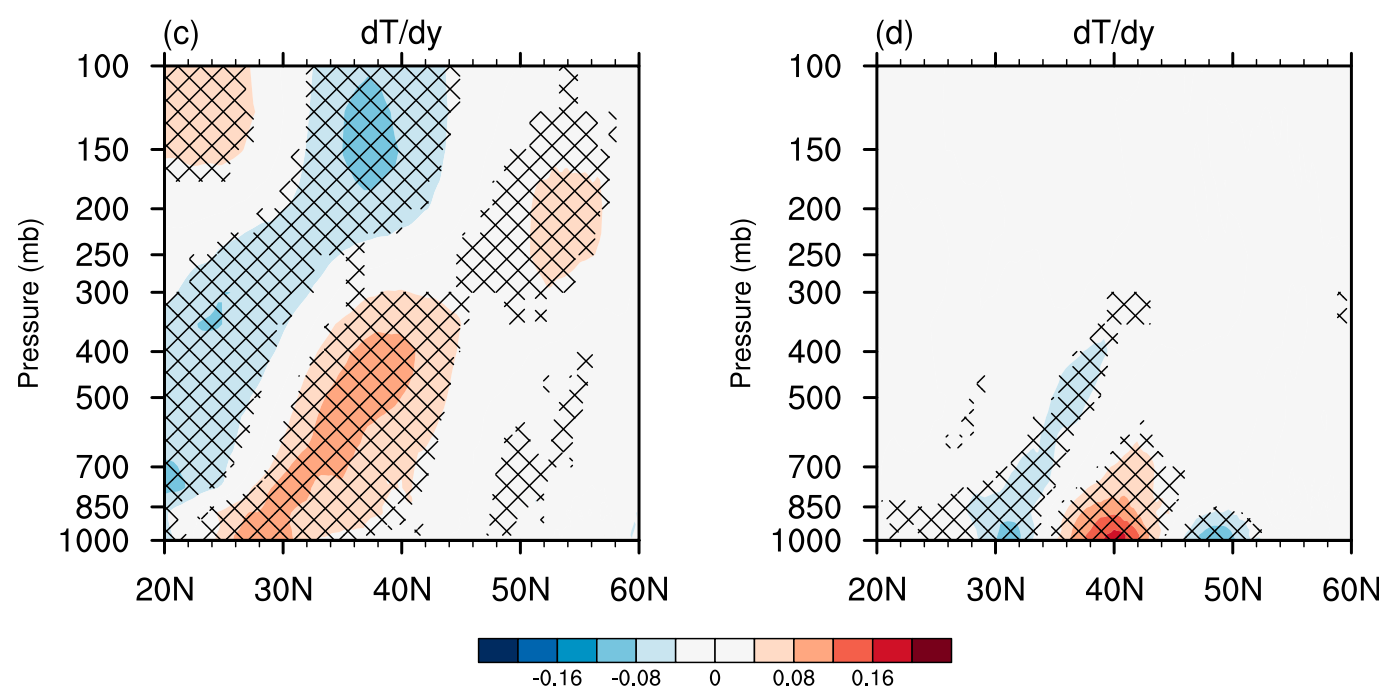

FIG. 13. The multiyear mean responses of (a) diabatic heating (shaded; $\mathrm{Kday}^{-1}$ ) and (c) meridional air temperature gradient [shaded; K $(100 \mathrm{~km})^{-1}$ ] to the STFZ, averaged between $140^{\circ} \mathrm{E}$ and $140^{\circ} \mathrm{W}$. (b), (d) As in (a) and (c), but for the responses to the SAFZ. Values above the $95 \%$ confidence level of Student's $t$ test are denoted by hatched lines.

acting to intensify and extend the jet stream and Aleutian low more eastward. The impacts of the SAFZ on the atmospheric circulations, however, exhibit strong year-by-year differences, although with consistent impacts on the lower-level baroclinicity and storm track. This suggests that, in addition to the SAFZ, the STFZ might be another predictor for the climate variability in the North Pacific and it is important to well simulate the STFZ to improve the performance of climate models.

Our study further highlights the role of diabatic heating for the different impacts of the STFZ and SAFZ on the wintertime atmospheric large-scale circulations.
The STFZ can induce deep diabatic heating, which not only results in the atmospheric response over the subtropical region with a vertically baroclinic structure via direct thermal forcing, but furthermore also changes the midlatitude baroclinicity through the whole troposphere, which is efficient for the generation of transient eddies from surface to upper levels. Such strong changes in transient eddies are responsible for the equivalent barotropic response of atmospheric circulations in our simulations and in the observations (Fang and Yang 2016). Recent studies by Wang et al. (2019) and Chen et al. (2019) investigated the atmospheric responses to 


\section{5/2016}

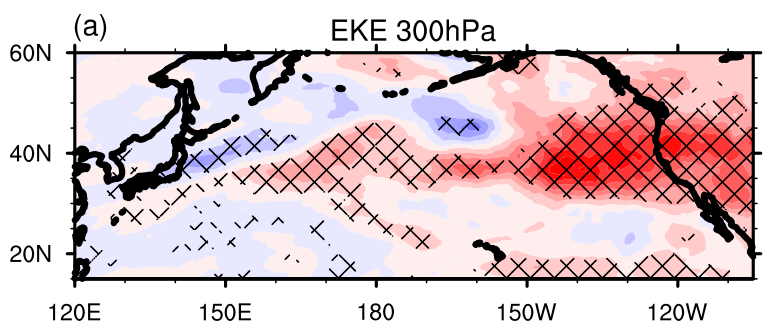

(c)

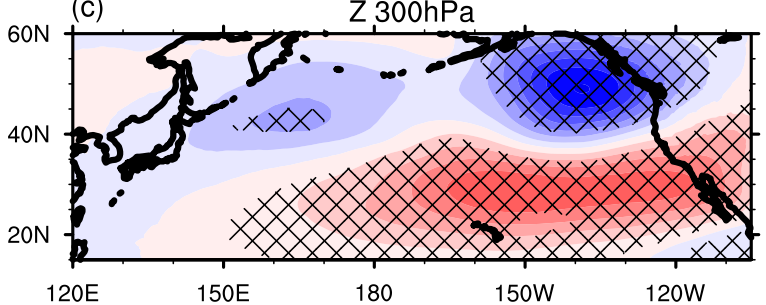

(b)

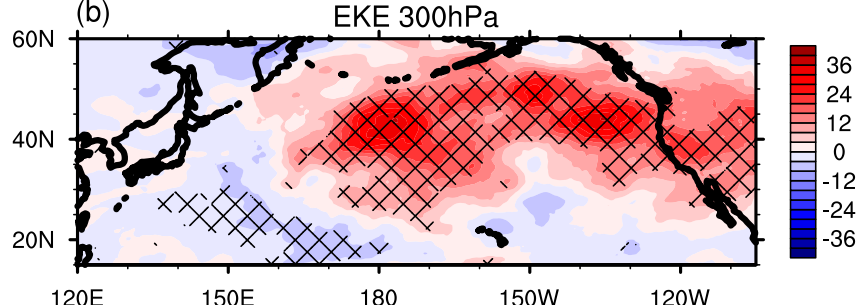

(d)

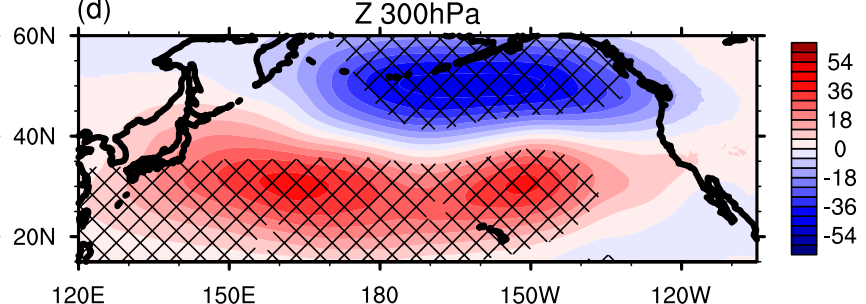

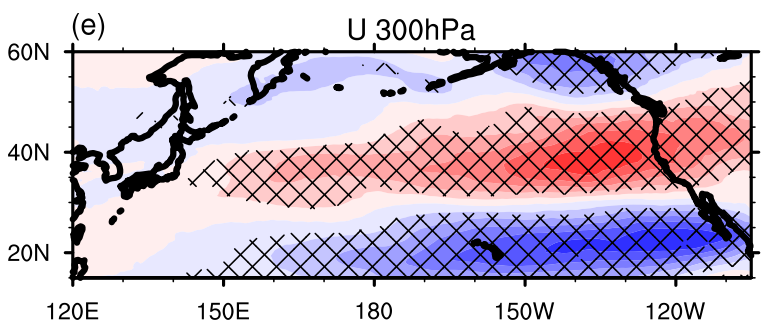

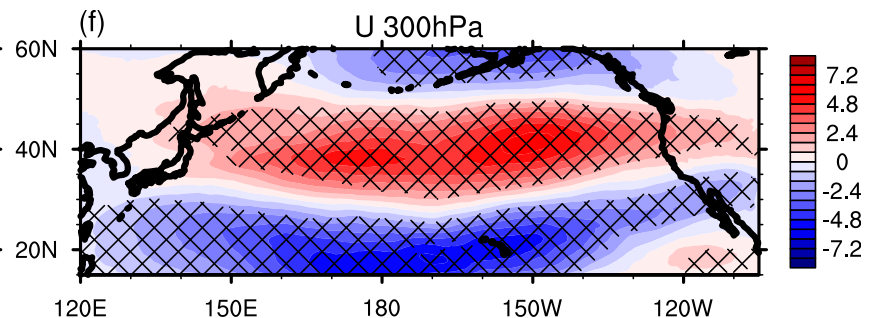

FIG. A1. The ensemble-mean responses of (a) synoptic transient eddy kinetic energy at $300 \mathrm{hPa}\left(\mathrm{m}^{2} \mathrm{~s}^{-2}\right)$, (c) geopotential height at $300 \mathrm{hPa}$ (shaded; $\mathrm{m}$ ), and (e) zonal wind at $300 \mathrm{hPa}$ (shaded; $\mathrm{m} \mathrm{s}^{-1}$ ) to the STFZ in the winter of 2015/16. (b), (d), (f) As in (a), (c), and (e), but for the winter of 2008/09. Values above the 95\% confidence level of Student's $t$ test are denoted by hatched lines.

STFZ-like forcing using model simulations with idealized zonally uniform SST and suggested the important role of transient eddy feedback. Our study, using observed SST, shows that the direct thermal forcing and the transient eddy feedback are both important in the atmospheric responses. The deep diabatic heating changes the upper-level baroclinicity, which can result in strong and consistent eddy responses.

We further investigate the mechanisms for the yearby-year difference of the atmospheric responses to the SAFZ. Compared to the deep diabatic heating with STFZ, the diabatic heating induced by the SAFZ is relatively shallow. With the shallower diabatic heating, the enhanced baroclinicity is confined in the lower level. We argue that the atmospheric responses to this shallow diabatic heating depend on the background mean states. When the background westerly jet is strong, the anomalous lower-level transient eddies can propagate to the upper troposphere and strong transient eddy-mean flow feedback occurs.
However, with weak background westerly jet, the anomalous transient eddies are confined in the lower level and cannot further affect the upper troposphere, consistent with the theoretical work by Nie et al. (2016). The background-state dependence for the atmospheric responses to the SAFZ helps us understand why the previous case studies obtained different responses of the atmospheric circulations, which probably relates to the different background states in those studies (Taguchi et al. 2009; Yao et al. 2016; Taguchi et al. 2012; O'Reilly and Czaja 2015; Kuwano-Yoshida and Minobe 2017).

Although our study identifies the critical role of the background state such as the westerly jet in the divergent eddy and circulation responses to SAFZ, the detailed mechanisms of background states affecting the atmospheric responses still needs further investigation. Recent studies such as that of Yuval and Kaspi (2018) suggest that not only the jet intensity, but also other characteristics such as the jet type also exert evident 
influences on eddy activity. The background atmospheric state in the wintertime North Pacific exhibits unique double baroclinic zones in the lower levels with the double oceanic fronts. The eddy-mean flow interactions in this unique situation call for more dynamical understandings. Furthermore, other factors of the background fields such as upstream seeding and tropical SST anomalies may modulate the atmospheric responses to the SAFZ as well (Orlanski 2005), which also needs further investigation. Owning to the fixed SST in our simulations, mesoscale SST structures such as mesoscale ocean eddies may not be well represented after the wintertime averaging. Given that mesoscale ocean eddies in the SAFZ can significantly affect atmospheric circulations through diabatic heating (Ma et al. 2015, 2017), our experiments may not well simulate such effect thus underestimate the atmospheric response to SAFZ. The impacts of SAFZ including both frontal-scale SST and mesoscale ocean eddies on atmospheric circulations worth evaluating in future studies.

In this study, as the first step to compare the different impacts of the two oceanic frontal zones, we separate the STFZ and SAFZ from each other and investigate the atmospheric responses to the fixed STFZ and SAFZ. In reality, there is relationship between the variabilities of the STFZ and SAFZ. Future work need to be conducted to investigate the atmospheric responses to the concurrent variabilities of the STFZ and SAFZ in a fully coupled air-sea system.

Acknowledgments. The authors thank the two anonymous reviewers for their constructive suggestions, which helped improve the quality of the manuscript. We also thank Prof. Hisashi Nakamura for the helpful discussions, who suggested us investigate the role of diabatic heating. This study was supported by the National Key Research and Development Program under Grant 2018YFC1506001, Strategic Priority Research Program of Chinese Academy of Sciences under Grant XDA20100312, and the National Natural Science Foundation of China under Grants 41675055 and 41621005. The FNL data were downloaded from https:// rda.ucar.edu/datasets/ds083.2/, and the CFSR atmospheric data were obtained from https://cfs.ncep.noaa.gov/cfsr/ downloads/. OAFlux data were obtained from http:// oaflux.whoi.edu/data.html.

\section{APPENDIX}

\section{Ensemble Simulations for STFZ Runs}

In our multiyear simulations, the atmospheric responses to STFZ (Fig. 5) are consistent in different winters. Here, we carry out the ensemble simulations, in which the internal atmospheric variability can be mostly eliminated, to further improve the robustness of the results. We still choose the winters of 2008/09 and $2015 / 16$ to carry out the ensemble simulations. Figure A1 shows the responses of upper-level storm track and atmospheric circulations to the STFZ, which exhibit similar patterns in the two winters both for upper-level storm track and atmospheric circulations, except that the response patterns are closer to the upstream region in the winter of 2008/09. Furthermore, the results in the two winters are all similar to the multiyear mean responses in Fig. 5, even with different background states. This again demonstrates that the STFZ exerts consistent impacts on the atmosphere in different winters.

\section{REFERENCES}

Betts, A. K., and M. J. Miller, 1986: A new convective adjustment scheme. Part II: Single column tests using GATE wave, BOMEX, ATEX and Arctic air-mass data sets. Quart. J. Roy. Meteor. Soc., 112, 693-709, https://doi.org/10.1002/ QJ.49711247308.

Brayshaw, D. J., B. Hoskins, and M. Blackburn, 2008: The stormtrack response to idealized SST perturbations in an aquaplanet GCM. J. Atmos. Sci., 65, 2842-2860, https://doi.org/ 10.1175/2008JAS2657.1.

Chen, F., and J. Dudhia, 2001: Coupling an advanced land surfacehydrology model with the Penn State-NCAR MM5 modeling system. Part I: Model implementation and sensitivity. Mon. Wea. Rev., 129, 569-585, https://doi.org/10.1175/1520-0493(2001) $129<0569$ :CAALSH $>2.0 . \mathrm{CO} ; 2$.

Chen, Q., H. Hu, X. Ren, and X.-Q. Yang, 2019: Numerical simulation of midlatitude upper-level zonal wind response to the change of North Pacific subtropical front strength. J. Geophys. Res., 124, 4891-4912, https://doi.org/10.1029/ 2018JD029589.

Deser, C., A. S. Phillips, M. A. Alexander, and B. V. Smoliak, 2014: Projecting North American climate over the next 50 years: Uncertainty due to internal variability. J. Climate, 27, 22712296, https://doi.org/10.1175/JCLI-D-13-00451.1.

Dinniman, M. S., and M. M. Rienecker, 1999: Frontogenesis in the North Pacific oceanic frontal zones: A numerical simulation. J. Phys. Oceanogr., 29, 537-559, https://doi.org/10.1175/ 1520-0485(1999)029<0537:FITNPO > 2.0.CO;2.

Dudhia, J., 1989: Numerical study of convection observed during the winter monsoon experiment using a mesoscale two-dimensional model. J. Atmos. Sci., 46, 3077-3107, https://doi.org/10.1175/1520-0469(1989)046<3077:NSOCOD> 2.0.CO;2.

Fang, J., and X. Yang, 2016: Structure and dynamics of decadal anomalies in the wintertime midlatitude North Pacific oceanatmosphere system. Climate Dyn., 47, 1989-2007, https:// doi.org/10.1007/s00382-015-2946-x.

Frankignoul, C., N. Sennéchael, Y.-O. Kwon, and M. A. Alexander, 2011: Influence of the meridional shifts of the Kuroshio and the Oyashio Extensions on the atmospheric circulation. J. Climate, 24, 762-777, https://doi.org/10.1175/ 2010JCLI3731.1. 
Hoskins, B. J., and D. J. Karoly, 1981: The steady linear response of a spherical atmosphere to thermal and orographic forcing. J. Atmos. Sci., 38, 1179-1196, https://doi.org/10.1175/ 1520-0469(1981)038<1179:TSLROA $>2.0 . \mathrm{CO} ; 2$.

_- , and P. J. Valdes, 1990: On the existence of stormtracks. J. Atmos. Sci., 47, 1854-1864, https://doi.org/10.1175/ 1520-0469(1990)047<1854:OTEOST>2.0.CO;2.

— I. I. James, and G. H. White, 1983: The shape, propagation and mean-flow interaction of large-scale weather systems. J. Atmos. Sci., 40, 1595-1612, https://doi.org/10.1175/ 1520-0469(1983)040<1595:TSPAMF $>2.0 . \mathrm{CO} ; 2$.

Janjić, Z. I., 1994: The step-mountain eta coordinate model: Further developments of the convection, viscous sublayer, and turbulence closure schemes. Mon. Wea. Rev., 122, 927-945, https:// doi.org/10.1175/1520-0493(1994)122<0927:TSMECM>2.0.CO;2.

Kazmin, A. S., and M. M. Rienecker, 1996: Variability and frontogenesis in the large-scale oceanic frontal zones. J. Geophys. Res., 101, 907-921, https://doi.org/10.1029/95JC02992.

Kelly, K. A., R. J. Small, R. M. Samelson, B. Qiu, T. M. Joyce, Y.-O. Kwon, and M. F. Cronin, 2010: Western boundary currents and frontal air-sea interaction: Gulf Stream and Kuroshio Extension. J. Climate, 23, 5644-5667, https:// doi.org/10.1175/2010JCLI3346.1.

Kushnir, Y., 1994: Interdecadal variations in North Atlantic sea surface temperature and associated atmospheric conditions. J. Climate, 7, 141-157, https://doi.org/10.1175/1520-0442(1994) 007<0141:IVINAS $>2.0$.CO;2.

Kuwano-Yoshida, A., and S. Minobe, 2017: Storm-track response to SST fronts in the northwestern Pacific region in an AGCM. J. Climate, 30, 1081-1102, https://doi.org/10.1175/JCLI-D-160331.1.

,-- , and S.-P. Xie, 2010: Precipitation response to the Gulf Stream in an atmospheric GCM. J. Climate, 23, 3676-3698, https://doi.org/10.1175/2010JCLI3261.1.

Kwon, Y.-O., M. A. Alexander, N. A. Bond, C. Frankignoul, H. Nakamura, B. Qiu, and L. A. Thompson, 2010: Role of the Gulf Stream and Kuroshio-Oyashio systems in large-scale atmosphere-ocean interaction: A review. J. Climate, 23, 32493281, https://doi.org/10.1175/2010JCLI3343.1.

Lee, S., and H.-K. Kim, 2003: The dynamical relationship between subtropical and eddy-driven jets. J. Atmos. Sci., 60, 1490-1503, https://doi.org/10.1175/1520-0469(2003)060<1490:TDRBSA > 2.0.CO;2.

Lim, K.-S. S., and S.-Y. Hong, 2010: Development of an effective double-moment cloud microphysics scheme with prognostic cloud condensation nuclei $(\mathrm{CCN})$ for weather and climate models. Mon. Wea. Rev., 138, 1587-1612, https://doi.org/ 10.1175/2009MWR2968.1.

Ma, C.-G., and E. K. M. Chang, 2017: Impacts of storm-track variations on wintertime extreme weather events over the continental United States. J. Climate, 30, 4601-4624, https:// doi.org/10.1175/JCLI-D-16-0560.1.

Ma, X., and Coauthors, 2015: Distant influence of Kuroshio eddies on North Pacific weather patterns? Sci. Rep., 5, 17785, https:// doi.org/10.1038/srep17785.

_- P. Chang, R. Saravanan, R. Montuoro, H. Nakamura, D. Wu, X. Lin, and L. Wu, 2017: Importance of resolving Kuroshio front and eddy influence in simulating the North Pacific storm track. J. Climate, 30, 1861-1880, https://doi.org/10.1175/JCLID-16-0154.1.

Minobe, S., A. Kuwano-Yoshida, N. Komori, S. P. Xie, and R. J. Small, 2008: Influence of the Gulf Stream on the troposphere. Nature, 452, 206-209, https://doi.org/10.1038/nature06690.
- M. Miyashita, A. Kuwano-Yoshida, H. Tokinaga, and S.-P. Xie, 2010: Atmospheric response to the Gulf Stream: Seasonal variations. J. Climate, 23, 3699-3719, https://doi.org/10.1175/ 2010JCLI3359.1.

Mlawer, E. J., S. J. Taubman, P. D. Brown, M. J. Iacono, and S. A. Clough, 1997: Radiative transfer for inhomogeneous atmospheres: RRTM, a validated correlated- $k$ model for the longwave. J. Geophys. Res., 102, 16 663-16682, https://doi.org/ 10.1029/97JD00237.

Nakamura, H., and T. Sampe, 2002: Trapping of synoptic-scale disturbances into the North-Pacific subtropical jet core in midwinter. Geophys. Res. Lett., 29, 1761, https://doi.org/ 10.1029/2002GL015535.

_ G. Lin, and T. Yamagata, 1997: Decadal climate variability in the North Pacific during the recent decades. Bull. Amer. Meteor. Soc., 78, 2215-2226, https://doi.org/10.1175/1520-0477(1997) 078<2215:DCVITN $>2.0$. CO;2.

_ T. Sampe, Y. Tanimoto, and A. Shimpo, 2004: Observed associations among storm tracks, jet streams and midlatitude oceanic fronts. Earth's Climate: The Ocean-Atmosphere Interaction, Geophys. Mongr., Vol. 147, Amer. Geophys. Union, 329-345, https://doi.org/10.1029/147GM18.

,,-- A. Goto, W. Ohfuchi, and S.-P. Xie, 2008: On the importance of midlatitude oceanic frontal zones for the mean state and dominant variability in the tropospheric circulation. Geophys. Res. Lett., 35, L15709, https://doi.org/10.1029/ 2008GL034010.

Nie, Y., Y. Zhang, G. Chen, and X.-Q. Yang, 2016: Delineating the barotropic and baroclinic mechanisms in the midlatitude eddydriven jet response to lower-tropospheric thermal forcing. J. Atmos. Sci. , 73, 429-448, https://doi.org/10.1175/JAS-D-15-0090.1.

Ogawa, F., H. Nakamura, K. Nishii, T. Miyasaka, and A. KuwanoYoshida, 2016: Importance of midlatitude oceanic frontal zones for the annular mode variability: Interbasin differences in the southern annular mode signature. J. Climate, 29, 61796199, https://doi.org/10.1175/JCLI-D-15-0885.1.

O'Reilly, C. H., and A. Czaja, 2015: The response of the Pacific storm track and atmospheric circulation to Kuroshio Extension variability. Quart. J. Roy. Meteor. Soc., 141, 52-66, https:// doi.org/10.1002/qj.2334.

_ S. Minobe, A. Kuwano-Yoshida, and T. Woollings, 2017: The Gulf Stream influence on wintertime North Atlantic jet variability. Quart. J. Roy. Meteor. Soc., 143, 173-183, https:// doi.org/10.1002/qj.2907.

Orlanski, I., 2005: A new look at the Pacific storm track variability: Sensitivity to tropical SSTs and to upstream seeding. J. Atmos. Sci., 62, 1367-1390, https://doi.org/10.1175/JAS3428.1.

Peng, S., W. A. Robinson, and M. P. Hoerling, 1997: The modeled atmospheric response to midlatitude SST anomalies and its dependence on background circulation states. J. Climate, 10, 971-987, https://doi.org/10.1175/1520-0442(1997)010<0971: TMARTM $>2.0 . \mathrm{CO} ; 2$.

Pleim, J. E., and J. S. Chang, 1992: A non-local closure model for vertical mixing in the convective boundary layer. Atmos. Environ., 26, 965-981, https://doi.org/10.1016/0960-1686(92) 90028-J.

Saha, S., and Coauthors, 2010: The NCEP Climate Forecast System Reanalysis. Bull. Amer. Meteor. Soc., 91, 1015-1057, https:// doi.org/10.1175/2010BAMS3001.1.

Sampe, T., H. Nakamura, A. Goto, and W. Ohfuchi, 2010: Significance of a midlatitude SST frontal zone in the formation of a storm track and an eddy-driven westerly jet. J. Climate, $\mathbf{2 3}$, 1793-1814, https://doi.org/10.1175/2009JCLI3163.1. 
Seo, H., Y.-O. Kwon, T. M. Joyce, and C. C. Ummenhofer, 2017: On the predominant nonlinear response of the extratropical atmosphere to meridional shifts of the Gulf Stream. J. Climate, 30, 9679-9702, https://doi.org/10.1175/JCLI-D-16-0707.1.

Skamarock, W. C., J. B. Klemp, J. Dudhia, D. O. Gill, D. M. Barker, W. Wang, and J. G. Powers, 2008: A description of the Advanced Research WRF version 3. NCAR/TN-475+STR, 113 pp., https://doi.org/10.5065/D68S4MVH.

Small, R. J., R. A. Tomas, and F. O. Bryan, 2014: Storm track response to ocean fronts in a global high-resolution climate model. Climate Dyn., 43, 805-828, https://doi.org/10.1007/ s00382-013-1980-9.

Taguchi, B., H. Nakamura, M. Nonaka, and S.-P. Xie, 2009: Influences of the Kuroshio/Oyashio Extensions on air-sea heat exchanges and storm-track activity as revealed in regional atmospheric model simulations for the 2003/04 cold season. J. Climate, 22, 6536-6560, https://doi.org/10.1175/ 2009JCLI2910.1.

N. Komori, A. Kuwano-Yoshida, K. Takaya, and A. Goto, 2012: Seasonal evolutions of atmospheric response to decadal SST anomalies in the North Pacific subarctic frontal zone: Observations and a coupled model simulation. J. Climate, 25, 111-139, https://doi.org/10.1175/JCLI-D-1100046.1.

Takeuchi, K., 1984: Numerical study of the Subtropical Front and the Subtropical Countercurrent. J. Oceanogr. Soc. Japan, 40, 371-381, https://doi.org/10.1007/BF02303341.

Tanimoto, Y., T. Kanenari, H. Tokinaga, and S.-P. Xie, 2011: Sea level pressure minimum along the Kuroshio and its extension. J. Climate, 24, 4419-4434, https://doi.org/10.1175/ 2011JCLI4062.1.
Thomson, S. I., and G. K. Vallis, 2018: Atmospheric response to SST anomalies. Part I: Background-state dependence, teleconnections, and local effects in winter. J. Atmos. Sci., $\mathbf{7 5}$, 4107-4124, https://doi.org/10.1175/JAS-D-17-0297.1.

Wang, L., H. Hu, and X. Yang, 2019: The atmospheric responses to the intensity variability of subtropical front in the wintertime North Pacific. Climate Dyn., 52, 5623-5639, https://doi.org/ 10.1007/S00382-018-4468-9.

Yamanaka, G., H. Ishizaki, M. Hirabara, and I. Ishikawa, 2008: Decadal variability of the Subtropical Front of the western North Pacific in an eddy-resolving ocean general circulation model. J. Geophys. Res., 113, C12027, https://doi.org/10.1029/ 2008JC005002.

Yao, Y., Z. Zhong, and X.-Q. Yang, 2016: Numerical experiments of the storm track sensitivity to oceanic frontal strength within the Kuroshio/Oyashio Extensions. J. Geophys. Res., 121, 2888-2900, https://doi.org/10.1002/2015JD024381.

$\mathrm{Yu}, \mathrm{L}$., and R. A. Weller, 2007: Objectively analyzed air-sea heat fluxes for the global ice-free oceans (1981-2005). Bull. Amer. Meteor. Soc., 88, 527-540, https://doi.org/10.1175/ BAMS-88-4-527.

Yuval, J., and Y. Kaspi, 2016: Eddy activity sensitivity to changes in the vertical structure of baroclinicity. J. Atmos. Sci., 73, 17091726, https://doi.org/10.1175/JAS-D-15-0128.1.

—, and —, 2018: Eddy sensitivity to jet characteristics. J. Atmos. Sci., 75, 1371-1383, https://doi.org/10.1175/JASD-17-0139.1.

Zeng, X.-M., and Coauthors, 2016: Effects of land surface schemes on WRF-simulated geopotential heights over China in summer 2003. J. Hydrometeor., 17, 829-851, https://doi.org/10.1175/ JHM-D-14-0239.1. 